\title{
Measuring Harbor Management, Stevedoring and Warehousing Performance of Taiwanese Container Ports Using the Multi-activity Network DEA Model
}

\author{
Ming-Miin $\mathrm{Yu}^{*}$, Bo Hsiao**, Shih-Hsun $\mathrm{Hsu}^{* * *}$, Shaw $\mathrm{Yu} \mathrm{Li}^{* * * *}$
}

\begin{abstract}
This paper presents an alternative approach to evaluating the overall efficiency and performance of Taiwanese container ports. Specifically, a parallel activity with series structure concept in the form of data envelopment analysis (MNDEA) is used to construct a model that applies to three different activities: harbor management, stevedoring and warehousing operations. We will further divide each activity into two process types, production processes and services processes. We will also adopt a Delphi survey approach and use the Analytic Network Process $(A N P)$ to identify these processes'influence dependence and their degree of importance for the MNDEA model setting. An empirical application demonstrates the performance of Taiwanese container ports by using MNDEA with window analysis techniques via the directional distance function.The results demonstrate that the application is effective in indicating and/or suggesting resource-adjustments, while considering which undesirable output levels and shared inputs were involved. The results also present directions for possible improvements in workplace efficiency.
\end{abstract}

Keywords: Multiple Activities Network Data Envelopment Analysis (MNDEA); Seaport operations; Performance evaluations; Window analysis: Analytic Network Process (ANP)

JEL Classification Numbers : M19

* Department of Transportation Science National Taiwan Ocean University, Keelung, 20224, Taiwan.

** Corresponding Author: Department of Information Management Chang Jung Christian University, Tainan, 71101, Taiwan. Email:; bhsiao@mail.cjcu.edu.tw

*** Department of Agricultural Economics National Taiwan University, Taipei, 10617, Taiwan.

**** Department of Transportation Science National Taiwan Ocean University, Keelung, 20224, Taiwan. 


\section{INTRODUCTION}

Recently, container port operations have become increasingly complex as new technologies impose new requirements in infrastructure and materials handling. When evaluating the functionality of port operations, analysts should not only examine harbor management activity, but also stevedoring and warehousing. Furthermore, some container ports' inputs are often shared amongst these activities, and all activities are involved in producing some outputs. Based on the interrelated nature of these activities and their diverse functions, conventional data envelopment analysis (DEA) cannot easily evaluate the efficiency of one activity from multiple others.

The majority of the previous studies (e.g., Park and De, 2004) have examined the efficiency of different container port activities by employing the data envelopment analysis approach, which uses a single activity to evaluate the efficiency while assuming that different activities can be aggregated. These studies implicitly assume that the different activities possess the same technology. However, a container port with a diverse set of activities has various available resources and characteristics; thus, each activity may have a different technology set.

Because facilities in a container port are hardly ever adjusted in short terms and ports are obliged to maintain minimum services which may result in deficits, port managers cannot curtail their services without first receiving permission during a given evaluation period. Therefore, the managers are responsible for decreasing inputs and keeping the provided capacity fixed at the predetermined level. This input-oriented perspective is suitable for the purposes of the production process, but on the other hand, the container port managers are also responsible for increasing operations while keeping the provided capacity unchanged (fixed at their predetermined level). This output-oriented perspective is more suitable for the purposes of the service process. Based on this concept, the predetermined capacity level can be viewed as output for the production process and input for the service process. Thus, each activity can be divided into a series of production and service processes (i.e., the two adjacent processes were connected together) to make the evaluation more realistic.

One problem with the single activity container port evaluation is the implicit assumption that all processes and activities equally affect the level of evaluation. This manipulation may lead to distort efficiency measurements.A few algorithms have been proposed in recent years for reducing the equal-weight effect (e.g., Yu and Lin, 2008; Thanassoulis and Dyson, 1992; Pastor et al.1999). However, those approaches assume that all processes or activities involved are non-interactive/independent. This assumption is not realistic in many real-world container port applications. Furthermore, these studies rarely discuss processes and activities with interaction. Because these processes 
and activities usually affect each other in their operations, it is unsuitable to use the single activity method, which assumes that these assessment processes and activities are independent. As a result, this study adopts an assessment process weighting model which uses the Delphi and ANP (Analytic Network Process) methods to resolve problems of activity interdependence.

Our approach uses multiple activities network data envelopment analysis (MNDEA), combined with Delphi/ANP techniques, to more easily measure the various activities with multiple processes in container port operations. The MNDEA allows us to not only estimate the performance of subsets of container ports, but also to deal with the problem of determining how often shared inputs areassociated with each activity simultaneously. These performance measures derived from the conventional network DEA model implicitly assume that each container port is equally efficient in all activities with series process, and that the container port is free to apply any of its inputs to any of its outputs in the most desirable way. In contrast, the MNDEA examines each activity and determines how much the shared inputs are associated with each activity simultaneously. Thus, the MNDEA can identify the particular advantages and disadvantagesof container ports by distinguishing which activities and processes are operating. In doing so, the MNDEA model is able to consider both desirable and undesirable outputs.

The contributions of this research to container port performance evaluation are threefold. First, the MNDEA model is the first proposed method to assess the operational efficiency of container ports with multiple activities considering the process/activity related to series-connected, parallel-connected, and shared inputs constraints. Secondly, the undesirable outputs which previous studies have ignored are taken into account in this paper. Third, we incorporate Delphi and ANP to determine the importance and influence between each process and the activity needed to generate a more realistic evaluative model.

The remainder of this paper is organized as follows. Section 2 reviews the current literature on container port performance evaluation. Section 3 describes our methodology. Section 4 reports our empirical results on data from the three main container ports from 1997 to 2008 in Taiwan. Section 5 summarizes our findings and their theoretical and managerial implications. Finally, section 6 offers conclusions and suggestions for future research.

\section{Literature Review}

Whilst there is extensive literature on benchmarking, applied to a wide diversity 
of economic areas, the container port sector is relatively under-researched. To date, most studies on container port efficiency evaluation have mainly focused on stochastic frontier analysis (SFA) (e.g., Cullinane and Song, 2003; Cuillinane et al. 2002; Estache et al. 2002; Liu, 1995), DEA (e.g., Barros and Athanassiou, 2004; Cullinane et al.2005; Roll and Hayuth, 1993; Valentine and Gray, 2001), multiple linear regression (e.g., Tongzon, 1995), total factor analysis (TFP)(e.g., Estache et al, 2004), and free disposal hull (FDH) (e.g., Wang et al. 2003; Cullinane et al. 2005). Among these analysis methods, DEA is considered to be one of the best approaches for organizing and analyzing data becauseit allows efficiency to evolve over time and requires no prior assumptions for the specification of the best-practice frontier.

There is extensive literature on DEA and it is applied to a wide diversity of economic topics and in particular to seaport transportation. Bendall and Stent (1987) considered cargo handling berth productivity as an efficient estimate of container ports. Roll and Hayuth (1993) have used the Charnes-Cooper-Rhodes (CCR) DEA model to evaluate and determine the efficiency of container ports. Their work was treated as a theoretical exploration for applying DEA to the seaport sector rather than as an actual application since no data was collected or analyzed. Later researchers have extended Roll and Hayuth's (1993) study, and used the Banker-Charnes-Cooper (BBC) DEA model to evaluate seaport efficiency by time series (Valentine and Gray, 2001). Valentine and Gray (2002) focused on the seaports of North America and Europe in order to compare efficiency, where they assumed that there are many factors for evaluating seaport performance, such as location, infrastructure and connectivity to other seaports. They used data from 1998 constituting thenumber of outputs, such as containers as total throughput, and inputs, such as the total length of berth, and container berth length. These authors concluded that DEA is useful for testingcontainer port efficiency and highlighted the characteristics of efficient seaports. Cullinnane et al. (2006) applied both approaches, DEA and SFA, to estimate the efficiency of the world's container terminals for the year 2001 and compared the obtained results. They concluded that the overall score from SFA was better than that of DEA, but that the cross-section data from one year may not be appropriate in order to capture multi-period optimization rather, SFA is more useful for a particular year.

Barros (2003) analyzed the total productivity change within a Portuguese container port using a two-stage Malmquist indexed model, where in the first stage an applied Malmquist index is estimated,followed by a Tobit regression estimation in the second stage. Barros (2006) evaluated the performance of 24 Italian container ports from the period 2002 to 2003 by using the DEA with CCR and BBC models. The outputs measured included liquid bulk, solid bulk, the number of containers, the number of ships, and total receipt, while the inputs measured were thenumber of 
personnel, the capital invested, and the value of operating costs. Cullinane et al. (2004) applied window analysis in order to evaluate the efficiency score of the world's major container seaports over time by using 1992-1999 panel data. They concluded that cross-section methods are unable to provide details for port performance, whereas panel data with window analysis reflects a variation of the absolute performance of a port over time, and the relative performance of that portcompared to others during the same period. Itoh (2002) analyzed efficiency changes at eight international container seaports in Japan, during the period 1990-1999 by using DEA window analysis. He found that Tokyo attained a higher efficiency score under CCR when compared to other seaports, owing to the operation scale of the ports.

The container port hosts multiple activities (e.g., tugging, pilot age), but container handling is the principal function of the container port, with handling constituting over $80 \%$ of the charges faced by a carrier bringing a container vessel intoa port for loading and unloading (Tovar, Trujillo and Jara-Diaz, 2004). Because variousactivities take place in a container port agents involved in container ports are diverse: port authorities, terminal operators, tug boats etc. Port containers were designed not only to improve handling efficiency andprimary port handling efficiency, but also for all handling between different transport modes. The basic function of a container port is to transfer goods between ships and shore and/or ship. In order to fulfill this most basic function, a container port provides different kindsof facilities and services. The World Bank classifies container port assets into four different categories: basic port infrastructure, operational infrastructure, superstructure and equipment (see Table 1).

Table 1.

The Four Different Assets of Container Ports

\begin{tabular}{cl}
\hline Type & \multicolumn{1}{c}{ Descriptions } \\
$\begin{array}{c}\text { Basic } \\
\text { Infrastructure }\end{array}$ & $\begin{array}{l}\text { Access channel, breakwater, locks, berths, rail and road } \\
\text { connections }\end{array}$ \\
$\begin{array}{c}\text { Operational } \\
\text { Infrastructure }\end{array}$ & $\begin{array}{l}\text { Inner channels and turning, revetments, quay walls, jetties, } \\
\text { navigation aids, buoys, beacons, moorings, docks }\end{array}$ \\
Superstructure & Paving, surfacing, lighting, offices, repair shops \\
Equipment & $\begin{array}{l}\text { Tugs, line handling vessels, dredging equipment, ship and shore } \\
\text { handling equipment, cargo handling equipment }\end{array}$ \\
\hline
\end{tabular}

Source: World Bank (2007, p.95)

After reviewing Table 1 and the previously published studies, we performed a variable selection and identified the following input/output variables in order to 
characterize the operation of the container port. Table 2 summarizes the measures used in defining container port inputs and outputs. However, previous studies (see Table 2) have not approached the problem from the undesirable perspective. In other words, undesirable outputs appear to have a harmful impact on the service of a decision making unit (DMU), in that they assume that undesirable outputs are accompanied by a reduction in desirable outputs or an increase in the use of inputs. Without considering the undesirable outputs into the evaluation, the efficiency evaluation methods may produce some misleading results (Lovell et al, 1995). To better understand this, our study used several undesirable factors in order to analyze Taiwan's container ports.

Table 2.

Summary of Papers Used in the Seaport Efficiency Evaluation

\begin{tabular}{|c|c|c|c|c|c|}
\hline Paper & Method & Observations & Periods & Inputs & Outputs \\
\hline $\begin{array}{l}\text { Cullinane et } \\
\text { al., (2002) }\end{array}$ & $\begin{array}{l}\text { Stochastic } \\
\text { Cobb-Douglas } \\
\text { production } \\
\text { frontier }\end{array}$ & $\begin{array}{l}15 \text { Asian } \\
\text { container } \\
\text { seaports }\end{array}$ & $\begin{array}{c}1989- \\
1998\end{array}$ & $\begin{array}{l}\text { Number of } \\
\text { employees }\end{array}$ & $\begin{array}{l}\text { Annual container } \\
\text { throughput in TEUs }\end{array}$ \\
\hline $\begin{array}{l}\text { Chung and } \\
\text { Hwang } \\
(2005)\end{array}$ & $\begin{array}{l}\text { DEA window } \\
\text { analysis }\end{array}$ & $\begin{array}{l}5 \text { Public } \\
\text { transportation } \\
\text { firms in } \\
\text { Taiwan }\end{array}$ & $\begin{array}{l}1999- \\
2001\end{array}$ & $\begin{array}{c}\text { Number of } \\
\text { employees, } \\
\text { total assets, } \\
\text { bulk carriers } \\
\text { Terminal }\end{array}$ & Shipping revues \\
\hline Itoh (2002) & $\begin{array}{l}\text { DEA window } \\
\text { analysis }\end{array}$ & $\begin{array}{l}8 \text { seaports in } \\
\text { Japan }\end{array}$ & $\begin{array}{l}1990- \\
1999\end{array}$ & $\begin{array}{l}\text { length, terminal } \\
\text { area, quayside } \\
\text { gantry } \\
\text { Labor }\end{array}$ & Container throughput \\
\hline $\begin{array}{l}\text { Tongzon and } \\
\text { Heng (2005) }\end{array}$ & $\begin{array}{l}\text { Applied SAF } \\
\text { proposed by } \\
\text { Battese and } \\
\text { Coelli in } \\
1995\end{array}$ & $\begin{array}{l}\text { A set of } \\
\text { terminals } \\
\text { around the } \\
\text { world }\end{array}$ & $\begin{array}{l}1995- \\
1997\end{array}$ & $\begin{array}{c}\text { Quay cranes, } \\
\text { quay } \\
\text { length, area }\end{array}$ & Container throughput \\
\hline Liu (1995) & $\begin{array}{l}\text { Translog } \\
\text { production } \\
\text { function } \\
\text { Panel data }\end{array}$ & $\begin{array}{l}28 \text { British } \\
\text { ports }\end{array}$ & $\begin{array}{c}1983- \\
1990\end{array}$ & $\begin{array}{l}\text { Movement of } \\
\text { freight (ton) }\end{array}$ & Turnover \\
\hline $\begin{array}{c}\text { Estache and } \\
\text { Trujillo } \\
(2001)\end{array}$ & $\begin{array}{l}\text { Translog and } \\
\text { Cobb- } \\
\text { Douglas } \\
\text { production } \\
\text { frontier model } \\
\text { Panel data }\end{array}$ & $\begin{array}{l}14 \text { Mexican } \\
\text { seaports }\end{array}$ & $\begin{array}{l}1996- \\
1999\end{array}$ & $\begin{array}{c}\text { Containers } \\
\text { handled (tons) }\end{array}$ & $\begin{array}{c}\text { Volume of } \\
\text { merchandise handled }\end{array}$ \\
\hline $\begin{array}{l}\text { Coto-Millán } \\
\text { and } \\
\text { Rodriguez- } \\
\text { Alvarez } \\
\text { (2000) }\end{array}$ & $\begin{array}{c}\text { Translog Cost } \\
\text { model Panel } \\
\text { data }\end{array}$ & $\begin{array}{l}27 \text { Spanish } \\
\text { Seaports }\end{array}$ & $\begin{array}{l}1985- \\
1989\end{array}$ & $\begin{array}{l}\text { Cargo handled } \\
\text { (ton) }\end{array}$ & $\begin{array}{l}\text { Aggregate port } \\
\text { output(includes total } \\
\text { goods moved in the } \\
\text { port in thousand } \\
\text { tones, the passenger } \\
\text { embarked and }\end{array}$ \\
\hline
\end{tabular}




\begin{tabular}{|c|c|c|c|c|c|}
\hline Paper & Method & Observations & Periods & Inputs & Outputs \\
\hline & & & & & $\begin{array}{l}\text { disembarked on } \\
\text { vehicles with } \\
\text { passengers) }\end{array}$ \\
\hline Barros (2006) & $\begin{array}{c}\text { DEA } \\
\text { Malmquist }\end{array}$ & $\begin{array}{l}24 \text { Italian } \\
\text { seaports }\end{array}$ & $\begin{array}{l}2002- \\
2003\end{array}$ & $\begin{array}{l}\text { Price of labor, } \\
\text { price of capital }\end{array}$ & Cargo and container \\
\hline Barros (2003) & $\begin{array}{l}\text { DEA-Malmqu } \\
\text { ist index and } \\
\text { a Tobit } \\
\text { model Panel } \\
\text { data }\end{array}$ & $\begin{array}{l}10 \text { Portuguese } \\
\text { seaports }\end{array}$ & $\begin{array}{l}1999- \\
2000\end{array}$ & $\begin{array}{l}\text { Number of } \\
\text { employees and } \\
\text { book value of } \\
\text { assets }\end{array}$ & $\begin{array}{l}\text { Ship, movement of } \\
\text { freight, break-solid } \\
\text { bulk cargo, } \\
\text { containers, solid, } \\
\text { liquid bulk }\end{array}$ \\
\hline $\begin{array}{l}\text { Tongzon } \\
\text { (2001) }\end{array}$ & $\begin{array}{l}\text { DEA-CCR } \\
\text { additive } \\
\text { Model. } \\
\text { Cross-section } \\
\text { data }\end{array}$ & $\begin{array}{l}4 \text { Australian } \\
\text { and } 12 \text { other } \\
\text { international, } \\
\text { Asian }\end{array}$ & 1996 & $\begin{array}{l}\text { Number of } \\
\text { cranes, number } \\
\text { of container } \\
\text { berth, number } \\
\text { of tugs, } \\
\text { terminal area, }\end{array}$ & $\begin{array}{l}\text { Cargo throughput, } \\
\text { ship work rate }\end{array}$ \\
\hline $\begin{array}{l}\text { Park \& } \\
\operatorname{De}(2004)\end{array}$ & $\begin{array}{l}\text { DEA-CCR } \\
\text { and } \mathrm{BCC}\end{array}$ & $\begin{array}{l}11 \text { Korean } \\
\text { seaports }\end{array}$ & 2001 & $\begin{array}{l}\text { Berthing } \\
\text { capacity, ships } \\
\text { calls, Cargo } \\
\text { handling(ton) }\end{array}$ & $\begin{array}{l}\text { Cargo throughput, } \\
\text { ships calls, revenue } \\
\text { and consumer } \\
\text { satisfaction }\end{array}$ \\
\hline $\begin{array}{l}\text { Notteboom et } \\
\text { al. (2000) }\end{array}$ & $\begin{array}{l}\text { Monte-Carlo } \\
\text { approximation }\end{array}$ & $\begin{array}{l}36 \text { European } \\
\text { container } \\
\text { terminals }\end{array}$ & 1994 & $\begin{array}{l}\text { Number of } \\
\text { cranes, Number } \\
\text { of employees }\end{array}$ & Container throughput \\
\hline Barros (2003) & $\begin{array}{l}\text { DEA-allocate } \\
\text { and Technical } \\
\text { Efficiency } \\
\text { Cross-section } \\
\text { data }\end{array}$ & $\begin{array}{l}5 \text { Portuguese } \\
\text { seaports }\end{array}$ & $\begin{array}{l}1999- \\
2000\end{array}$ & $\begin{array}{c}\text { Number of } \\
\text { employees, } \\
\text { book value of } \\
\text { assets }\end{array}$ & $\begin{array}{c}\text { Ships, } \\
\text { movement of freight, } \\
\text { gross tonnage, } \\
\text { market share, } \\
\text { break-bulk, liquid } \\
\text { bulk, containers, } \\
\text { Ro-Ro, salaries } \\
\text { labor, capital }\end{array}$ \\
\hline
\end{tabular}

\section{Modeling and Problem Formulation}

In this study, we view a container port as only having three activities: harbor management, stevedoring and warehousing activities. Harbor management activity refers to vessel arrival, port management, and ship management including shipping and scheduling demand. Stevedoring activity means cargo loaded and unloaded from ships. Since cargo movement at container ports is generally a 24-hour, seven days a week job, Stevedores work in shift patterns to ensure that there is always cover on the dock when a ship needs loading or unloading, and as a result stevedoring activity cannot be ignored. Lastly, warehousing activity contains a wharf's schedule and adjustments, as well as imports, exports and trainload goods storage services.

Despite the growing amount of research related to container-port operations and efficiency, most of the literature on the subject treats container port operations as a 
black box system without examining the structure of their activities and processes in its operation. In this paper, we argue that container terminal production is better evaluated as a serial network with parallel activities. We develop a multi-activity network DEA model aimed at capturing the processes within the container-terminal system by attempting to understand shared inputs across the activities, and the bundling of undesirable outputs.

The present investigation is motivated by the lack of available analyses regarding container port's performance in parallel activities that contain series processes and produce undesirable outputs. The following section briefly introduces the modeling concepts employed for efficiency evaluation among container ports constrained by a small number of decision-making units (DMUs).

\subsection{Problem Descriptions and Modeling Formations}

Before describing our proposed framework, some assumptions and terms need to be clarified. First, as described above, we assume that container port operations are responsible for three tasks: harbor management activity (hereafter called HA), stevedoring activity (hereafter called SA) and warehousing activity (hereafter called WA). Each activity can be divided into the production process and the services process for each specific container port $k$, as shown in Figure 1. Capacity variables serve as an intermediary between the two processes. We also assume that the management of the container port is unable to manipulate these capacity variables in the short-run. This implies that a container port's activity involves series processes, rather than the single-process perspective. Second, due to resource control ability constraints, there is no overlap among output variables, while inputs share characteristics between activities. Third, for increasing discriminating power, we employed the window analysis technique to extend the number of DMUs ${ }^{1}$. Table 3 shows the notations for the abovementioned notes and definitions.

Table 3.

Description of Notations

\begin{tabular}{cl}
\hline Variable /Notation & \multicolumn{1}{c}{ Definition/Item } \\
$n$ & Number of container ports \\
$h$ & Harbor management activity \\
$s$ & Stevedoring activity
\end{tabular}

1) In order to capture the variations of efficiency over time, Charnes et al. (1985) proposed a technique called 'window analysis' in DEA. 


\begin{tabular}{|c|c|}
\hline Variable /Notation & Definition/Item \\
\hline$w$ & Warehousing activity \\
\hline$k(k=h, s, w)$ & Indexes for activities \\
\hline$n_{s}^{k}$ & Number of specific input variable $S$ of the activity $k$ \\
\hline$n_{c}^{h, s}$ & $\begin{array}{l}\text { Number of common input variable } c \text { between activities } h \\
\text { and } S \text {. }\end{array}$ \\
\hline$n_{g}^{s, w}$ & $\begin{array}{l}\text { Number of common input variable } g \text { between activities } S \\
\text { and } w \text {. }\end{array}$ \\
\hline$n_{d}^{k}$ & Number of intermediate desirable output $d$ of activity $k$ \\
\hline$n_{f}^{k}$ & Number of final desirable output $f$ of activity $k$. \\
\hline$N$ & Number of container ports \\
\hline$n_{o}^{k}$ & Number of final undesirable output $O$ of activity $k$ \\
\hline$\left.j_{(j}=1, \ldots, N\right)$ & Indexes for container ports \\
\hline$s\left(s=1, . ., n_{s}^{k}\right)$ & Indexes for specific input variable $S$ of activity $k$ \\
\hline$c\left(c=1, . ., n_{c}^{h, s}\right)$ & $\begin{array}{l}\text { Indexes for common input variable } c \text { shared between activities } \\
h \text { and } S \text {. }\end{array}$ \\
\hline$g\left(g=1, . ., n_{g}^{s, w}\right)$ & $\begin{array}{l}\text { Indexes for common input variable } g \text { shared between activities } \\
S \text { and } w \text {. }\end{array}$ \\
\hline$d\left(d=1, \ldots, n_{d}^{k}\right)$ & $\begin{array}{l}\text { Indexes for intermediate desirable output variable } d \text { of } \\
\text { activity } k \text {. }\end{array}$ \\
\hline$\left.f_{(} f=1, \ldots, n_{f}^{k}\right)$ & 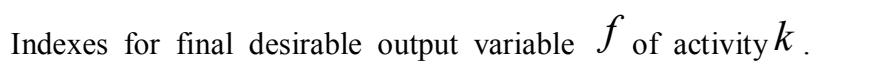 \\
\hline$o\left(o=1, \ldots, n_{o}^{k}\right)$ & Indexes for final undesirable output variable $O$ of activity $k$ \\
\hline$t=1 \cdots T$ & Indexes for time-period \\
\hline$x_{s j}^{k}$ & The specific input variable $S$ of activity $k$ of container port $j$ \\
\hline$x_{c j}^{h, s}$ & $\begin{array}{l}\text { The common input variable } c \text { shared between activity } h \text { and } \\
S \text { of container port } j \text {. }\end{array}$ \\
\hline$x_{g j}^{s, w}$ & $\begin{array}{l}\text { The common input } g \text { shared between activity } S \text { and } w \text { of } \\
\text { container port } j \text {. }\end{array}$ \\
\hline$y_{d j}^{k}$ & $\begin{array}{l}\text { The intermediate desirable output variable } d \text { of activity } k \text { of } \\
\text { container port } j \text {. }\end{array}$ \\
\hline$y_{f j}^{k}$ & zut variable $f$ of activity $k$ of container port $j$ \\
\hline
\end{tabular}




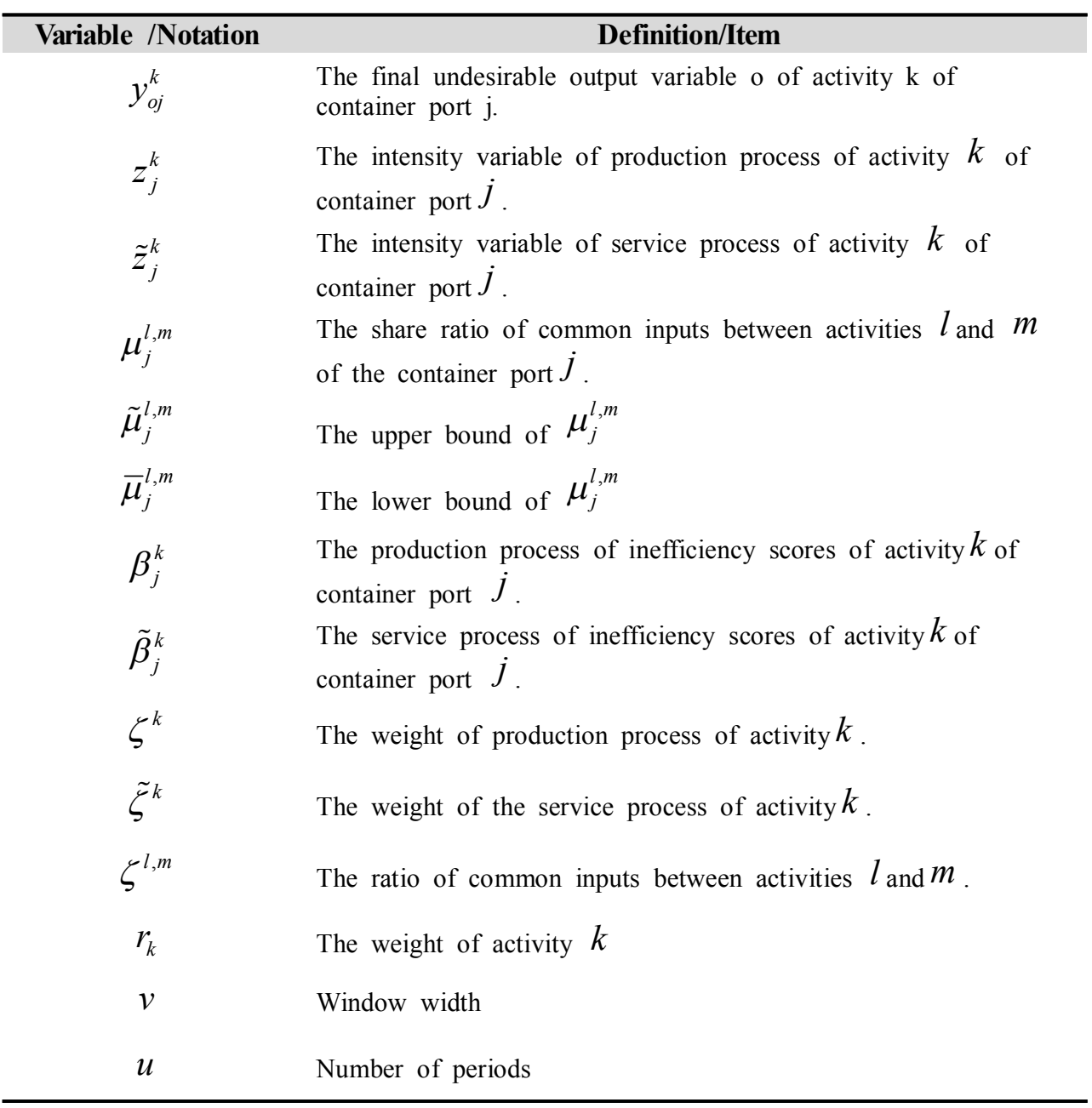

The traditional DEA model evaluates the efficiency with which a DMU transforms inputs from a black-box to outputs, as shown in the Figure 1 dash line. It assumes that a DMU is equally efficient in all of its activities (e.g., Park and De, 2004). However, there are cases in which a DMU may face several production activities. This may happen when a DMU is engaged in several activities simultaneously, for example, a container port that operates HA, SA and WA activities. Furthermore, a container port efficient in HA may not be efficient in SA or WA, and thus different efficiency ratings for different activities should be distinguished. When a DMU jointly carries out various activities and processes which cannot be assumed to be technologically identical, these activities and processes are separated into different technologies in a multi-activity DEA model (Mar Molinero, 1996). 
Figure 1 further outlines the structure of our model. For each container port $k$, port operations are assessed for three activities (including the use of parallel structures), and each activity can be divided into two processes. The production process transfers the original inputs for maintaining their capacities and the production efficiency (PE) is examined (i.e., HPP, SPP, WPP).The second process, known as the service process uses its previous process capacities as inputs in order to produce service outputs, including both undesirable and desirable outputs, the service efficiency (SE) is then examined (i.e., HSP, SSP, WSP), In the evaluation of the production process, it can be understood that if input resources are used inadequately, it will lead to waste. Alternatively, service inefficiency is measured as the utilization of production capacity. Overall port operational efficiency $(\mathrm{OE})$ is determined by the above described parallel activities-series processes connection of the network data envelopment analysis (NDEA) structure.

\section{Figure 1.}

The Structure of Container Port's Activities

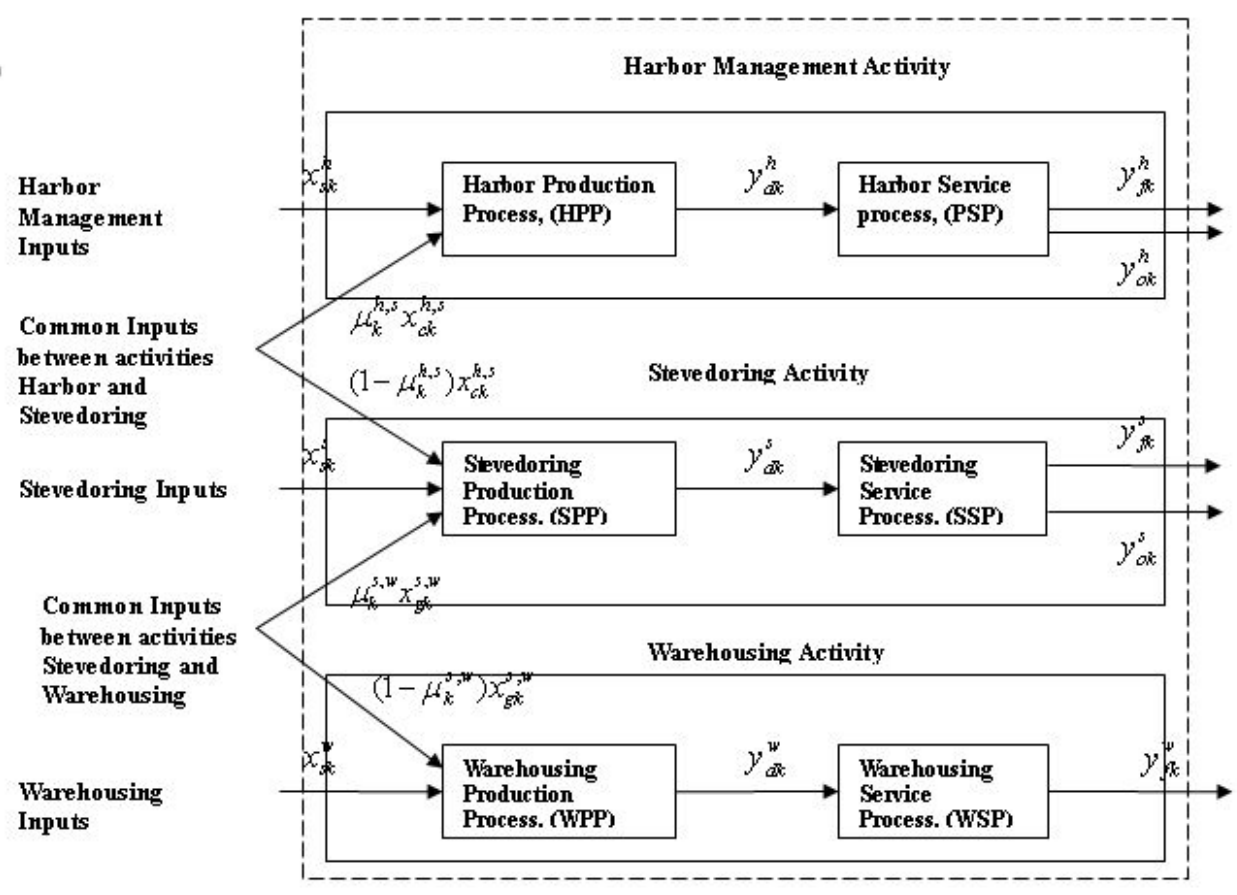




\subsection{Container Port's Production Possibility Set (PPS)}

Following the system architecture of container port operations mentioned above, consider a three-activity container port embodied by two series processes, as depicted in Figure 1. The major difference between the MNDEA model and the single activity DEA model is the allocation of shared inputs between the three activities in the MNDEA model. Each process technology set is depicted as follows:

\section{Harbor Management Production Process (HPP) Production Possibility Set}

Our MNDEA model enables us to acquire moreinsight into how inputs can be shared between activities and the inter-related effects between different activities and processes. For a specific container port $k$, in the MNDEA content, the HPP production possibility set (PPS) for a containerport is defined as thefollowing:

$$
T_{H P P}\left(x_{s k}^{h}, x_{c k}^{h, s} ; y_{d k}^{h}\right)=\left\{\begin{array}{l}
\sum_{j=1}^{N} z_{j}^{h} x_{s j}^{h} \leq x_{s k}^{h}, s=1, \ldots, n_{s}^{h} ; \\
\sum_{j=1}^{N} z_{j}^{h} \mu_{j}^{h, s} x_{c j}^{h, s} \leq \mu_{k}^{h, s} x_{c k}^{h, s}, c=1, \ldots, n_{c}^{h, s} ; \\
\sum_{j=1}^{N} z_{j}^{h} y_{d j}^{h} \geq y_{d k}^{h}, d=1, \ldots, n_{d}^{h} ; \\
z_{j}^{h} \geq 0 ; \mu_{j}^{h, s} \in\left[\bar{\mu}_{j}^{h, s}, \tilde{\mu}_{j}^{h, s}\right] ; j=1, \ldots, n ;
\end{array}\right.
$$

The constraints that define $T_{H P P}\left(x_{s k}^{h}, x_{c k}^{h, s} ; y_{d k}^{h}\right)$ imply that the set of outputs, $\left(y_{d k}^{h}\right)$, is such that a production process can produce no more of the output, using no less of the specific and common inputs, than a combination of all DMUs' observations on outputs and inputs. The constraints requiring $z_{j}^{h} \geq 0$ for all $j=1, \ldots, n$ DMUs yield constant returns to scale technology. The second part of the constraint illustrates that the commoninputs contribute to the ratio of $\mu_{j}^{h, s}$ to the HPP, and the ratio of common inputs contributes to production and lies in a given range between $\left[\bar{\mu}_{j}^{h, s}, \tilde{\mu}_{j}^{h, s}\right]$. 
Similar to $T_{H P P}\left(x_{s k}^{h}, x_{c k}^{h, s} ; y_{d k}^{h}\right)$, we define the stevedoring production process (SPP) Production Possibility Set as:

$$
T_{S P P}\left(x_{s k}^{s}, x_{g k}^{s, w}, x_{c k}^{h, s} ; y_{d k}^{s}\right)=\left\{\begin{array}{l}
\sum_{j=1}^{N} z_{j}^{s} x_{s k}^{s} \leq x_{s k}^{s}, s=1, \ldots, n_{s}^{s} ; \\
\sum_{j=1}^{N} z_{j}^{s}\left(1-\mu_{j}^{h, s}\right) x_{c j}^{h, s} \leq\left(1-\mu_{k}^{h, s}\right) x_{c k}^{h, s}, c=1, \ldots, n_{c}^{h, s} ; \\
\sum_{j=1}^{N} z_{j}^{s} \mu_{j}^{s, w} x_{g j}^{s, w} \leq \mu_{j}^{s, w} x_{g k}^{s, w}, g=1, \ldots, n_{g}^{s, w} ; \\
\sum_{j=1}^{N} z_{j}^{s} y_{d j}^{s} \geq y_{d k}^{s}, d=1, \ldots, n_{d}^{s} ; \\
z_{j}^{s} \geq 0 ; \mu_{j}^{s, w} \in\left[\bar{\mu}_{j}^{s, w}, \tilde{\mu}_{j}^{s, w}\right] ; \mu_{j}^{h, s} \in\left[\bar{\mu}_{j}^{h, s}, \tilde{\mu}_{j}^{h, s}\right] ; j=1, \ldots, N ;
\end{array}\right.
$$

The Warehousing Production Process (WPP) Production Possibility Set as

$$
T_{W P P}\left(x_{s k}^{w}, x_{g k}^{s, w} ; y_{d k}^{w}\right)=\left\{\begin{array}{l}
\sum_{j=1}^{N} z_{j}^{w} x_{s k}^{w} \leq x_{s k}^{w}, s=1, \ldots, n_{s}^{w} ; \\
\sum_{j=1}^{N} z_{j}^{w}\left(1-\mu_{j}^{s, w}\right) x_{g j}^{s, w} \leq\left(1-\mu_{k}^{s, w}\right) x_{g k}^{s, w}, g=1, \ldots, n_{g}^{s, w} \\
\sum_{j=1}^{N} z_{j}^{w} y_{d j}^{w} \geq y_{d k}^{w}, d=1, \ldots, n_{d}^{w} ; \\
z_{j}^{w} \geq 0 ; \mu_{j}^{s, w} \in\left[\bar{\mu}_{j}^{s, w}, \tilde{\mu}_{j}^{s, w}\right] ; j=1, \ldots, n
\end{array}\right.
$$

\section{The Harbor Management Services Process (HSP)Production Possibility Set}

If we model the HSS technology by imposing the null-jointness between desirable and undesirable outputs as well as weak disposability, the $\mathrm{T}_{H S P}$ is an output set as $\left(y_{f}, y_{o}\right) \in \mathrm{T}_{H S P}$ and $1 \leq \theta \leq 1$ imply $\left(\theta y_{f}, \theta y_{o}\right) \in \mathrm{T}_{H S P}$. In other words, this means that a reduction in undesirable outputs is feasible only if desirable outputs are simultaneously reduced, given a fixed level of inputs. In addition, we assume that desirable outputs are freely $\operatorname{disposable}\left(y_{f}, y_{o}\right) \in \mathrm{T}_{H S P}$ and $y_{f}^{\prime} \leq y_{f} \quad$ imply $\left(y_{f}^{\prime}, y_{o}\right) \in \mathrm{T}_{H S P}$. The notion that the desirable outputs are jointly produced with the 
undesirable outputs is modeled if $\left(y_{f}, y_{o}\right) \in \mathrm{T}_{H S P}$ and $y_{o}=0$ then $y_{f}=0$. This means that if a good output is produced in a positive amount some bad output must also be produced (Chung et al., 1997).

The constraints which define $T_{H S P}\left(y_{d k}^{h}, y_{o k}^{h}, y_{f k}^{h}\right)$ imply that the set of final outputs, $\left(y_{o k}^{h}, y_{f k}^{h}\right)$, is such that the service process can produce no more of the good output (due to strong disposability), than an equal amount of the bad output (due to weak disposability), using no less intermediate outputs from the previous harbor managementproduction process, than a combination of all ports' observations on good final outputs, bad final outputs, and intermediate outputs from the previous process. The constraints also require $z_{j}^{w} \geq 0$ for all $j=1, \ldots, n$ ports to yield the constant returns for scale technology.

$$
T_{H S P}\left(y_{d k}^{h}, y_{o k}^{h}, y_{f k}^{h}\right)=\left\{\begin{array}{l}
\sum_{j=1}^{N} \tilde{z}_{j}^{h} y_{d j}^{h} \leq y_{d k}^{h}, d=1, \ldots, n_{d}^{h} ; \\
\sum_{j=1}^{N} \tilde{z}_{j}^{h} y_{f j}^{h} \geq y_{f k}^{h} ; f=1, \ldots, n_{f}^{h} \\
\sum_{j=1}^{N} \tilde{z}_{j}^{h} y_{o j}^{h}=y_{o k}^{h} ; o=1, \ldots, n_{o}^{h} ; \\
\tilde{z}_{j}^{h} \geq 0 ; j=1, \ldots, N ;
\end{array}\right.
$$

Similar to $T_{H P P}\left(x_{s k}^{h}, x_{c k}^{h, s} ; y_{d k}^{h}\right)$, we define the stevedoring services process (SSP) Production Possibility Set as:

$$
T_{S S P}\left(y_{d k}^{s}, y_{o k}^{s}, y_{f k}^{s}\right)=\left\{\begin{array}{l}
\sum_{j=1}^{N} \tilde{z}_{j}^{s} y_{d j}^{s} \leq y_{d k}^{s}, d=1, \ldots, n_{d}^{s} ; \\
\sum_{j=1}^{N} \tilde{z}_{j}^{s} y_{f j}^{s} \geq y_{f k}^{s}, f=1, \ldots, n_{f}^{s} ; \\
\sum_{j=1}^{N} \tilde{z}_{j}^{s} y_{o j}^{s}=y_{o k}^{s}, o=1, \ldots, n_{o}^{s} ; \\
\tilde{z}_{j}^{s} \geq 0 ; j=1, \ldots, N ;
\end{array}\right.
$$


Since there is no undesirable output produced in this process, the traditional output possibilityset is used to characterize technology for the Warehousing Services Process (WSP) Production Possibility Set as

$$
T_{W S S}\left(y_{d k}^{w}, y_{o k}^{w}, y_{f k}^{w}\right)=\left\{\begin{array}{l}
\sum_{j=1}^{N} \tilde{z}_{j}^{w} y_{d j}^{w} \leq y_{d k}^{w} ; d=1, \ldots, n_{d}^{w} ; \\
\sum_{j=1}^{N} \tilde{z}_{j}^{w} y_{f j}^{w} \geq y_{f k}^{w} ; f=1, \ldots, n_{f}^{w} \\
\tilde{z}_{j}^{w} \geq 0 ; j=1, \ldots ., N
\end{array}\right.
$$

Thus, the operational possibility set corresponding to the port's operation is expressed as Set (7)

$$
\mathbf{T}=\mathbf{T}_{H P S} \cup \mathbf{T}_{S P P} \cup \mathbf{T}_{W P P} \cup \mathbf{T}_{H S P} \cup \mathbf{T}_{S S P} \cup \mathbf{T}_{W S P}
$$

\subsection{MNDEA by using Directional Distance Functions}

When evaluating the performance of container ports, it is worth noting that since capacity cannot be stored, the output consumption may be substantially different from the output production. To illustrate this type of constraint within our model, we adopt the capacity variables as intermediate variables. Moreover, capacity is treated as a fixed intermediate product which acts as an output of the production process and an input of service process due to the limitation of possible adjustments in the short-term. The capacity is not easy to adjust in the short-term, which implies that the input-oriented approach is better to model than the first process (i.e., the production process) and the output-oriented approach for the second process (i.e., services process). Furthermore, based on directional distance function manipulation, the $k-t$ th container port's HPP inefficiency score $\beta_{k}^{h}$ can be represented as the directional distance function defined by the technology $T_{H P P}$. This definition of the inefficiency score $\beta_{k}^{h}$ implies that the directional input distance function is used to gauge the performance of the production process of a container port, as in Model (8). 


$$
\left.\vec{D}_{i}^{H P P}=\sup \left\{\beta_{k}^{h}:\left(1-\beta_{k}^{h}\right) x_{s k}^{h},\left(1-\beta_{k}^{h}\right) x_{c k}^{h, s}, y_{d k}^{h}\right] \in \mathbf{T}_{H P P}\right\}
$$

Similar to Model (8), the $k-t h$ container's SPP efficiency measure can be represented as Model (9) by using the directional input distance function

$$
\left.\vec{D}_{i}^{S P P}=\sup \left\{\beta_{k}^{s}:\left(1-\beta_{k}^{s}\right) x_{s k}^{s},\left(1-\beta_{k}^{s}\right)\left(1-\mu_{k}^{h, s}\right) x_{c k}^{h, s},\left(1-\beta_{k}^{s}\right) \mu_{k}^{s, w} x_{g k}^{s, w}, y_{d k}^{s}\right] \in \mathbf{T}_{S P P}\right\}
$$

The $k$-th container port's WPP inefficiency score can be represented as Model (10) by using the directional input distance function

$$
\left.\vec{D}_{i}^{W P P}=\sup \left\{\beta_{k}^{w}:\left(1-\beta_{k}^{w}\right) x_{s k}^{w},\left(1-\beta_{k}^{w}\right)\left(1-\mu_{k}^{s, w}\right) x_{c k}^{s, w}, y_{d k}^{w}\right] \in \mathbf{T}_{W P P}\right\}
$$

In order to allow for the possibility of crediting ports for the reduction of bad outputs,we use a directional output distance function to represent technology. In contrast to the directional input distance function which seeks to decrease specific and common inputs simultaneously, the directional output distance function seeks to increase the good final outputs while simultaneously decreasing the bad final outputs. Therefore, the HSP, SSP and WSP can be represented as Models (11), (12) \& (13), respectively.

$$
\begin{aligned}
& \left.\vec{D}_{o}^{H S P}=\sup \left\{\tilde{\beta}_{k}^{h}: y_{d k}^{h},\left(1+\tilde{\beta}_{k}^{h}\right) y_{f k}^{h},\left(1-\tilde{\beta}_{k}^{h}\right) y_{o k}^{h}\right] \in \mathbf{T}_{H S P}\right\} \\
& \left.\vec{D}_{o}^{S S P}=\sup \left\{\tilde{\beta}_{k}^{s}: y_{d k}^{s},\left(1+\tilde{\beta}_{k}^{s}\right) y_{f k}^{s},\left(1-\tilde{\beta}_{k}^{s}\right) y_{o k}^{s}\right] \in \mathbf{T}_{S S P}\right\}
\end{aligned}
$$

The WSP can be represented as Model (13).

$$
\left.\vec{D}_{o}^{W S P}=\sup \left\{\tilde{\beta}_{k}^{w}: y_{d k}^{w},\left(1+\tilde{\beta}_{k}^{w}\right) y_{f k}^{w}\right] \in \mathbf{T}_{W S P}\right\}
$$

where $\tilde{\beta}_{k}^{h}, \tilde{\beta}_{k}^{s}$ and $\tilde{\beta}_{k}^{w}$ represent the inefficiency scores of HSP, SSP and WSP for container port $\mathrm{k}$, respectively.

\subsection{The MNDEA measure}

Having formalized the MDEA technology described in Fig. 1, the directional distance function is then applied to construct our MNDEA modeland determine the measurement. The MNDEA model is defined in this study as follows: 


$$
\operatorname{Max} r_{h}\left[\zeta^{h} \beta_{k}^{h}+\tilde{\zeta}^{h} \tilde{\beta}_{k}^{h}\right]+r_{s}\left[\zeta^{s} \beta_{k}^{s}+\tilde{\zeta}^{s} \tilde{\beta}_{k}^{s}\right]+r_{w}\left[\zeta^{w} \beta_{k}^{w}+\tilde{\zeta}^{w} \tilde{\beta}_{k}^{w}\right]
$$

\section{HA Constraint Set}

\section{HPP without considering the common inputs Constraint Set}

Since the capacity of a harbor is not easy to change in the short-term, the input-oriented perspective is used to evaluate the HPP performance, as Eqs. (14.2)-(14.3).

$$
\begin{aligned}
& \sum_{j=1}^{N} z_{j}^{h} x_{s j}^{h} \leq\left(1-\beta_{k}^{s}\right) x_{s k}^{h}, s=1, \ldots, n_{s}^{h}, \\
& \sum_{j=1}^{N} z_{j}^{h} y_{d j}^{h} \geq y_{d k}^{h}, d=1, \ldots, n_{d}^{h},
\end{aligned}
$$

\section{$\underline{\text { HSP Constraint Set }}$}

From the output-oriented perspective, the Eqs. (14.4)-(14.6) are used to evaluate the service process at a fixed level of capacity provided by the previous HPP.

$$
\begin{aligned}
& \sum_{j=1}^{N} \tilde{z}_{j}^{h} y_{d j}^{h} \leq y_{d k}^{h}, d=1, \ldots, n_{d}^{h}, \\
& \sum_{j=1}^{N} \tilde{z}_{j}^{h} y_{f j}^{h} \geq\left(1+\tilde{\beta}_{k}^{h}\right) y_{f k}^{h}, f=1, \ldots, n_{f}^{h}, \\
& \sum_{j=1}^{N} \tilde{z}_{j}^{h} y_{o j}^{h}=\left(1-\tilde{\beta}_{k}^{h}\right) y_{o k}^{h}, o=1, \ldots, n_{o}^{h}
\end{aligned}
$$

\section{$\underline{\text { SA Constraint Set }}$}

\section{SPP without considering the common inputs Constraint Set}

Similar to the $\boldsymbol{H A}$ Constraint Set, the SPP and SSP Constraint Sets are as follows: Eqs (14.7)-(14.8) and Eqs (14.9)-(14.11), respectively.

$$
\sum_{j=1}^{N} z_{j}^{s} x_{s j}^{s} \leq\left(1-\beta_{k}^{s}\right) x_{s k}^{s}, s=1, \ldots, n_{s}^{s},
$$




$$
\sum_{j=1}^{N} z_{j}^{s} y_{d j}^{s} \geq y_{d k}^{s}, d=1, \ldots, n_{d}^{s}
$$

\section{SSP Constraint Set}

$$
\begin{aligned}
& \sum_{j=1}^{N} \tilde{z}_{j}^{s} y_{d j}^{s} \leq y_{d k}^{s}, d=1, \ldots, n_{d}^{s}, \\
& \sum_{j=1}^{N} \tilde{z}_{j}^{s} y_{f j}^{s} \geq\left(1+\tilde{\beta}_{k}^{s}\right) y_{f k}^{s}, f=1, \ldots, n_{f}^{s}, \\
& \sum_{j=1}^{N} \tilde{z}_{j}^{s} y_{o j}^{s}=\left(1-\tilde{\beta}_{k}^{s}\right) y_{o k}^{s}, o=1, \ldots, n_{o}^{s}
\end{aligned}
$$

\section{WA Constraint Set}

\section{WPP without considering the common inputs Constraint Set}

Similarly, Eqs (14.12)-(14.13) are imposed as an input-orientation WPP technology set, Eqs (14.14)-(14.15) as an output-orientation WSPP technology set

$$
\begin{aligned}
& \sum_{j=1}^{N} z_{j}^{w} x_{s j}^{w} \leq\left(1-\beta_{k}^{w}\right) x_{s k}^{w}, s=1, \ldots, n_{s}^{w}, \\
& \sum_{j=1}^{N} z_{j}^{w} y_{d j}^{w} \geq y_{d k}^{w}, d=1, \ldots, n_{d}^{w},
\end{aligned}
$$

\section{WSP Constraint Set}

$$
\begin{aligned}
& \sum_{j=1}^{N} \tilde{z}_{j}^{w} y_{d j}^{w} \leq y_{d k}^{w}, d=1, \ldots, n_{d}^{w}, \\
& \sum_{j=1}^{N} \tilde{z}_{j}^{w} y_{f j}^{w} \geq\left(1+\tilde{\beta}_{k}^{w}\right) y_{f k}^{w}, f=1, \ldots, n_{f}^{w},
\end{aligned}
$$

\section{Common Inputs between HPP and SPP}

It is assumed that some portion $1 \mu_{j}^{h, s}$ of the common input $\mathrm{c}$ shared between HPP and SPP is allocated to the HPP, and the remainder $1-\mu_{j}^{h, s}$ is allocated to the $\mathrm{SPP}$, in which $\mu_{j}^{h, s}$ is a decision variable to be determined by the DMU k. 


$$
\begin{aligned}
\sum_{j=1}^{N} \mu_{j}^{h, s} z_{j}^{h} x_{c j}^{h, s} & +\sum_{j=1}^{N}\left(1-\mu_{j}^{h, s}\right) z_{j}^{s} x_{c j}^{h, s} \leq \\
& {\left[\left(1-\beta_{k}^{h}\right) \mu_{k}^{h, s}+\left(1-\beta_{k}^{s}\right)\left(1-\mu_{k}^{h, s}\right)\right] x_{c k}^{h, s}, \mathrm{c}=1, \ldots, n_{c}^{h, s} }
\end{aligned}
$$

\section{Common Inputs between SPP and WPP}

Similarly, some portion $1_{j}^{s, w}$ of this common input c shared between SPP and WPP is allocated to the SPP, and the remainder $1-\mu_{j}^{s, w}$ is allocated to the WPP, in which $\mu_{j}^{s, w}$ is also a decision variable to be determined by the DMU $\mathrm{k}$.

$$
\begin{aligned}
\sum_{j=1}^{N} \mu_{j}^{s, w} z_{j}^{s} x_{g j}^{s, w} & +\sum_{j=1}^{N}\left(1-\mu_{j}^{s, w}\right) z_{j}^{w} x_{g j}^{s, w} \leq \\
& {\left[\left(1-\beta_{k}^{s}\right) \mu_{j}^{s, w}+\left(1-\beta_{k}^{w}\right)\left(1-\mu_{k}^{s, w}\right)\right] x_{g k}^{s, w}, \mathrm{~g}=1, \ldots, n_{g}^{s, w} }
\end{aligned}
$$

\section{Additional Constraint Set}

$$
\begin{aligned}
& z_{j}^{h}, \tilde{z}_{j}^{h}, z_{j}^{s}, \tilde{z}_{j}^{s}, z_{j}^{w}, \tilde{z}_{j}^{w} \geq 0 ; \forall j \\
& \forall \zeta^{h}, \tilde{\zeta}^{h}, \zeta^{s}, \tilde{\zeta}^{s}, \zeta^{w}, \tilde{\zeta}^{w} \geq 0, \\
& \zeta^{s}+\tilde{\zeta}^{s}=1, \\
& \zeta^{s}+\tilde{\zeta}^{s}=1 \\
& \zeta^{w}+\tilde{\zeta}^{w}=1(14.22) \\
& r_{h}+r_{s}+r_{w}=1(14.23) \\
& \bar{\mu}_{j}^{h, s} \leq \mu_{j}^{h, s} \leq \tilde{\mu}_{j}^{h, s} ; \forall j \\
& \bar{\mu}_{j}^{s, w} \leq \mu_{j}^{s, w} \leq \tilde{\mu}_{j}^{s, w} ; \forall j
\end{aligned}
$$

where $z_{j}^{h}$ and $\tilde{z}_{j}^{h}$ are intensity variables corresponding to the HPP and HSP processes, respectively. They served to shrink or expand the individually observed processes of harbor activity of DMU $\mathrm{j}$ for the purpose of constructing convex combinations of the observed inputs and outputs, thereby forming the piecewise linear best practice reference technology. Similarly, $z_{j}^{h}$ and $\tilde{z}_{j}^{h}$ are intensity variables 
corresponding to the SPP and SSP processes, respectively. $z_{j}^{h}$ and $\tilde{z}_{j}^{h}$ are intensity variables corresponding to the WPP and WSP processes, respectively.

Under these constraints (Eqs. 14.2-14.25), the solution to the objective function is evaluated by maximizing the weighted average inefficiencies of the production and service process in each of the three activities, with the given weights of $\left(\zeta^{h}, \tilde{\zeta}^{h}\right),\left(\zeta^{s}, \tilde{\zeta}^{s}\right),\left(\zeta^{w}, \tilde{\zeta}^{w}\right) . \quad r_{h}, r_{s}, r_{w}$ These are the scalars associated with the relative importance or priorities of the three activities of port operation, such that $\zeta^{s}+\tilde{\zeta}^{s}=1, \quad \zeta^{s}+\tilde{\zeta}^{s}=1, \zeta^{w}+\tilde{\zeta}^{w}=1, \quad \zeta$ and $\tilde{\zeta}$ are weights to the production and service processes, respectively. $r_{h}+r_{s}+r_{w}=1, r_{h}, r_{s}, r_{w}$ are the weights to HA, SA and WA respectively. Eq. (14.1) takes a value of zero if and only if the container ports' HA, SA, and WA are all simultaneously technically efficient and all of the six sub-processes are simultaneously effective. Eq. (14.1) takes a value greater than zero if and only if the container port is technically inefficient and at least one of the six sub-processes is ineffective.

\subsection{Window Analysis}

One of the issues in many DEA studies is the dimensionality problem, which is the number of inputs and outputs, relative to the number of observations in the cross-section. This can be crucial when the number of observations is relatively small compared to the total number of variables (Leibenstein and Maital, 1992). There is no exact rule for the number of cross-sectional observations required. Charnes and Cooper (1990) state that the window analysis can be used in order for the DEA model to be discriminatory.

In order to deal with the problem of a small number of container ports compared to the number of inputs and outputs in this study, we use the window analysis approach with a window width of $v$ years. This means that observations are only compared to other observations within a time span of $v$ years. The window width of $v$ years is selected to be large enough to achieve a sufficient sample size for the analysis. The observations for the decision making units in different years are treated as separate observations, and all are measured against each other. Given the number of container ports (n) and periods $(u)$ that we have collected, we assume that we know the length of the window $(v)$. For each period, we run $u-v+1$ times the inefficiency scores for $N$ container ports, with each single period of container ports being dependent. For example, in the first window, the inefficiency scores of $n$ 
container ports in the first $v$ periods are measured. Then, the second window will contain the $\mathrm{n}$ container port from the 2 nd to $(v+1)-t h$ periods, and so on. The last window will include those container ports from $(u-v)$ th to $v-t h$ periods. Figure 2 shows the inefficiency score of each period in each window. These $\mathrm{w}$ scores are then averaged as the $u-t h$ inefficiency score for any of the container ports.

Figure 2 .

The windows analysis

\begin{tabular}{|c|c|c|c|c|c|c|c|c|c|c|}
\hline \multirow{2}{*}{$\begin{array}{l}\text { Container } \\
\text { Port }\end{array}$} & \multirow{2}{*}{ Window } & \multicolumn{9}{|c|}{ Inefficiency scores } \\
\hline & & 1 & 2 & $u$ & $u+1$ &.. & $v-u$ & .. &.. & $v$ \\
\hline \multirow{4}{*}{ Keelung } & 1 & & & & & & & & & \\
\hline & 2 & & & & & & & & & \\
\hline & & $\cdot$ & & & & & & & & \\
\hline & $v-u+1$ & & & & & & & & & \\
\hline \multirow{4}{*}{ Taichung } & 1 & & & & & & & & & \\
\hline & 2 & & & & & & & & & \\
\hline & & & & & & & & & & \\
\hline & $v-u+1$ & & & & & & & & & \\
\hline \multirow{4}{*}{ Kaohsiung } & 1 & & & & & & & & & \\
\hline & 2 & & & & & & & & & \\
\hline & & & & & & & & & & \\
\hline & $v-u+1$ & & & & & & & & & \\
\hline
\end{tabular}

\subsection{Degree of Influence and Weighting for Each Process}

In addition to the window analysis, we also determine the importance for each process in our model. Traditionally, the analytic hierarchy process (AHP) has been widely used in DEA to assign each process a weighting for various applications (Seiford and Zhu, $1998 \mathrm{Yu}$ and Lin, 2009). However, when using AHP, researchers must assume that all of the processes are non-interactive or independent. This assumption is unrealistic for container ports. In order to overcome the problems of interdependence and the interaction between processes and activities in the container port setting, we must adopt the analytic network process (ANP) approach. ANP is an extension of AHP; indeed, it is the general form of AHP. Although both AHP and ANP derive ratio scale priorities by making pair wised comparisons of processes/activities, they also have some key differences. First, ANP deals with dependence within a cluster (inner dependence) and among different clusters (outer 
dependence), and it is a nonlinear structure. In contrast, AHP is hierarchical and linear with the goal placed at the top of the hierarchy. ANP does not require this strictly hierarchical structure, and a single network or a number of networks may be included in an ANP model. Many past studies have used ANP and have provided additional information on its usage (Tzeng et al., 2005, Tzeng et al., 2006).

\section{Empirical Results}

This section outlines the empirical analysis in this study. The steps can be divided into four subparts: (i) data preprocessing; (ii) weight calculation, which determines the importance of each process of each activity (iii) window analysis, wherein the number of observations can be expand and (iv) efficiency score estimation.

\subsection{Data and Input-output Variables}

Data are obtained from the Institute of Transportation of the Ministry of Transportation and Communications (MOTC) in Taiwan, consisting of a ten-year (1999-2008) sample size that includes Taiwan's six major international sea ports: Taipei, Keelung, Taichung, Hualien, Suao and Kaohsiung. Two seaports, Hualien and Suao, do not run container operations, and have thus been removed from the sample. Taipei is also excluded, due to incomplete cross-sectional data (e.g., data tables do not list three activities from the same time period) or longitudinal gaps. Thus, the remaining observations consisted of data from three container ports (Taichung, Keelung and Kaohsiungports) from 1999 to 2008.

While Table 3 in Section 2 provides a variable specification, when considering undesirable outputs in each activity, were fer to the Annual Reports from the Institute of the MOTC. These outputs include a ships-time-in-port and a ships-waiting-time-for berth for the harbor management activities, and the turnaround-time for stevedoring activities. These three time measurements are related to time, where longer time measurements are less desirable. Among the three activities, there are two common inputs: number of berthing, which involves work for HA and SA, and straddle carriers, which is work for both HA and WA. Regarding straddle carriers, there are two reasons for listing it as a common input within this study. While straddle carriers may officially belong to one activity, they are actually responsible for multiple jobs (e.g., storage, transportation and distribution) among multiple places (i.e., the marshaling yard, consolidation shed and container wharf). Table 4 outlines the variable parameters and definitions, while descriptive statistics of the data are presented in Tables 5-7. 
Taiwanese Container Ports Using the Multi-activity Network DEA Model

Table 4.

Measures of Inputs and Outputs for the Container Ports

\begin{tabular}{|c|c|c|c|c|}
\hline \multirow{2}{*}{ Activity } & \multirow{2}{*}{ Inputs } & \multirow{2}{*}{ Capacity } & \multicolumn{2}{|c|}{ Output } \\
\hline & & & Desirable & Undesirable \\
\hline HA & 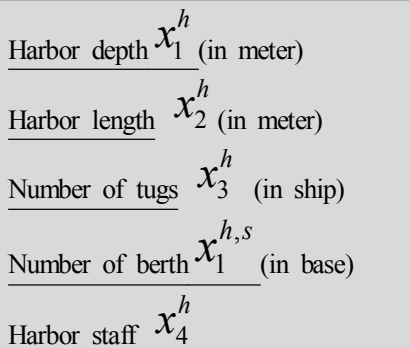 & $\frac{\text { Terminal }}{y_{d 1}^{h}}$ (in & $\begin{array}{l}\text { Gross Tonnage } \\
y_{f 1 \text { (in thousand }}^{h} \\
\text { ton) }\end{array}$ & $\begin{array}{l}\text { Ships waiting time for } \\
\text { berth } y_{o 1}^{h} \text { (in hour) }\end{array}$ \\
\hline SA & $\begin{array}{l}\frac{\text { Gantry crane }}{x_{1}^{s} \text { (in machine) }} \\
\frac{\text { Number of berth } x_{1}^{h, s}}{\text { Straddle carrier } x_{1}^{s, w} \text { (in base) }} \text { (in machine) } \\
\text { Dockers } x_{2}^{s} \text { (in person) }\end{array}$ & $\begin{array}{l}\text { Handling capacity } \\
y_{d 1}^{s} \text { (in thousand } \\
\text { ton) }\end{array}$ & $\begin{array}{l}\frac{\text { Cargo lifting } y_{f 1}^{s}}{\text { (in ton) }} \\
\frac{\text { Container handling }}{y_{f 2}^{s} \text { (in TEU) }}\end{array}$ & $\begin{array}{l}\text { Turnaround time } \\
y_{o 1}^{s} \text { (in hour) }\end{array}$ \\
\hline WA & $\begin{array}{l}\frac{\text { Stacker }}{x_{1}^{w} \quad \text { (in machine) }} \\
\frac{\text { Man-hour }}{x_{2}^{w} \text { (in hour) }} \\
\underline{\text { Straddle carrier }} x_{1}^{s, w} \text { (in machine) } \\
\text { Area of wharf } x_{3}^{w} \text { (in hectare) }\end{array}$ & $\begin{array}{l}\frac{\text { Capacity of warehouse }}{\text { field } y_{d 1}^{w} \text { ( in tone) }} \\
\frac{\text { Capacity of container }}{\frac{\text { stacked field }}{\text { (in TEU) }} y_{d 2}^{w}}\end{array}$ & $\begin{array}{l}\text { Capacity of storage } \\
\frac{\text { in ton-day }}{y_{f 1}^{w}} \\
\text { in Ton-day) }\end{array}$ & \\
\hline
\end{tabular}


Table 5.

Descriptive Statistics Data for Inputs from the Three Container Portsfrom 1999-2008

\begin{tabular}{ccccccccccccc}
\hline \multirow{2}{*}{ Port } & & $x_{1}^{h}$ & $x_{2}^{h}$ & $x_{3}^{h}$ & $x_{4}^{h}$ & $x_{1}^{s}$ & $x_{1}^{h, s}$ & $x_{2}^{h, s}$ & $x_{1}^{w}$ & $x_{2}^{w}$ & $x_{1}^{s, w}$ & $x_{3}^{w}$ \\
\hline \multirow{5}{*}{ Keelung } & Max & 14.5 & 9985.7 & 57.0 & 18.0 & 8.0 & 30.0 & 10.0 & 206.0 & 1066.0 & 25.0 & 196.4 \\
& Min & 13.5 & 9903.0 & 37.0 & 14.0 & 4.0 & 22.0 & 3.0 & 27.0 & 605.0 & 21.0 & 196.4 \\
& Avg & 14.3 & 9926.6 & 44.6 & 15.8 & 6.4 & 27.6 & 5.6 & 96.5 & 789.6 & 22.7 & 196.4 \\
& Std & 0.4 & 27.7 & 8.5 & 1.8 & 1.5 & 2.2 & 2.2 & 68.3 & 130.0 & 1.5 & 0.0 \\
\hline \multirow{6}{*}{ Taichung } & Max & 18.0 & 11536.0 & 48.0 & 14.0 & 71.0 & 13.0 & 27.0 & 115.0 & 808.0 & 32.0 & 1530.9 \\
& Min & 18.0 & 9337.0 & 38.0 & 10.0 & 50.0 & 11.0 & 19.0 & 78.0 & 529.0 & 26.0 & 1345.0 \\
& Avg & 18.0 & 10739.1 & 44.2 & 10.6 & 58.5 & 12.6 & 22.7 & 96.0 & 667.6 & 27.2 & 1448.7 \\
& Std & 0.0 & 628.5 & 3.4 & 1.3 & 7.3 & 0.8 & 2.5 & 13.7 & 85.1 & 2.5 & 66.6 \\
\hline \multirow{6}{*}{ Kaohsiung } & Max & 16.5 & 26598.0 & 150.0 & 31.0 & 60.0 & 65.0 & 23.0 & 167.0 & 3838.0 & 81.0 & 1442.3 \\
& $\operatorname{Min}$ & 16.5 & 25140.0 & 85.0 & 25.0 & 31.0 & 36.0 & 9.0 & 26.0 & 2850.0 & 53.0 & 1442.3 \\
& Avg & 16.5 & 26451.8 & 98.1 & 27.4 & 41.6 & 56.1 & 16.6 & 71.2 & 3225.8 & 68.9 & 1442.3 \\
& Std & 0.0 & 460.9 & 27.4 & 2.1 & 9.0 & 9.3 & 4.4 & 50.5 & 292.6 & 7.6 & 0.0 \\
\hline
\end{tabular}

Table 6.

Descriptive Statistics Data for Capacity from the Three Container Ports from 1999-2008

\begin{tabular}{rrrrrr}
\hline \multirow{2}{*}{ Port } & & \multicolumn{1}{c}{$y_{d 1}^{h}$} & $y_{d 1}^{s}$ & $y_{d 1}^{w}$ & $y_{d 2}^{w}$ \\
\hline \multirow{3}{*}{ Keelung } & Max & 128505 & 42 & 140867 & 298692 \\
& Min & 108166 & 40 & 128212 & 273871 \\
& Avg & 115803 & 40.6 & 135873.1 & 283197.9 \\
& Stdev & 6298.89 & 0.7 & 4028.63 & 9943.44 \\
\hline \multirow{3}{*}{ Taichung } & Max & 136589 & 48 & 265444 & 1887804 \\
& Min & 56632 & 39 & 244128 & 1775484 \\
& Avg & 109095.3 & 44.9 & 246259.6 & 1865340 \\
& Stdev & 29661.7 & 2.56 & 6740.71 & 47358.27 \\
\hline \multirow{2}{*}{ Kaohsiung } & Max & 613455 & 94 & 937936 & 118302 \\
& Min & 254150 & 86 & 541962 & 108302 \\
& Avg & 575859.8 & 90.9 & 836085.8 & 115318 \\
& Stdev & 113158.3 & 2.81 & 159285.3 & 4804.89 \\
\hline
\end{tabular}


Taiwanese Container Ports Using the Multi-activity Network DEA Model

Table 7.

Descriptive Statistics for Outputs from the Three Container Ports from 1999-2008

\begin{tabular}{ccccccccc}
\hline Port & & $y_{f 1}^{h}$ & $y_{o 1}^{h}$ & $y_{o 2}^{h}$ & $y_{f 1}^{s}$ & $y_{o 1}^{s}$ & $y_{o 2}^{s}$ & $y_{f 1}^{w}$ \\
\hline \multirow{6}{*}{ Keelung } & Max & 121046.0 & 35.2 & 6.2 & 23874168.0 & 24.4 & 2215484.0 & 166395057.0 \\
& Min & 95151.1 & 24.8 & 0.3 & 16579608.0 & 20.4 & 1665622.0 & 18663284.0 \\
& Avg & 109842.2 & 28.1 & 2.9 & 19719460.0 & 21.5 & 1991659.0 & 76027797.4 \\
& Stdev & 9192.5 & 3.3 & 2.1 & 2837069.8 & 1.4 & 160927.6 & 53539967.4 \\
\hline \multirow{5}{*}{ Taichung } & Max & 78596.3 & 37.3 & 7.9 & 47176920.0 & 36.3 & 1394003.0 & 461283388.0 \\
& Min & 71021.4 & 30.4 & 0.7 & 36871004.0 & 29.5 & 1069361.0 & 256320668.0 \\
& Avg & 76341.0 & 33.7 & 4.5 & 41589096.9 & 32.7 & 1207096.3 & 338303568.3 \\
& Stdev & 2217.1 & 2.2 & 2.7 & 3597055.9 & 2.2 & 91770.0 & 75050334.3 \\
\hline \multirow{6}{*}{ Kaohsiung } & Max & 384268.0 & 43.4 & 2.3 & 119204430.0 & 34.6 & 10256830.0 & 1695171880.0 \\
& Min & 299262.0 & 31.5 & 0.1 & 100636502.0 & 27.7 & 6985366.0 & 7276510.0 \\
& Avg & 345245.7 & 36.8 & 0.6 & 108885299.0 & 30.2 & 8818313.7 & 509793361.2 \\
& Stdev & 30956.2 & 4.4 & 0.8 & 5713571.7 & 2.5 & 1153933.1 & 801865798.2 \\
\hline
\end{tabular}

\subsection{Weighting Calculation}

Based on the selected variables mentioned above, we draw the following hierarchical structure diagram (Figure 3). Here, the black bold line represents an interactive relationship between processes/activities. 


\section{Figure 3.}

The study hierarchical structure diagram

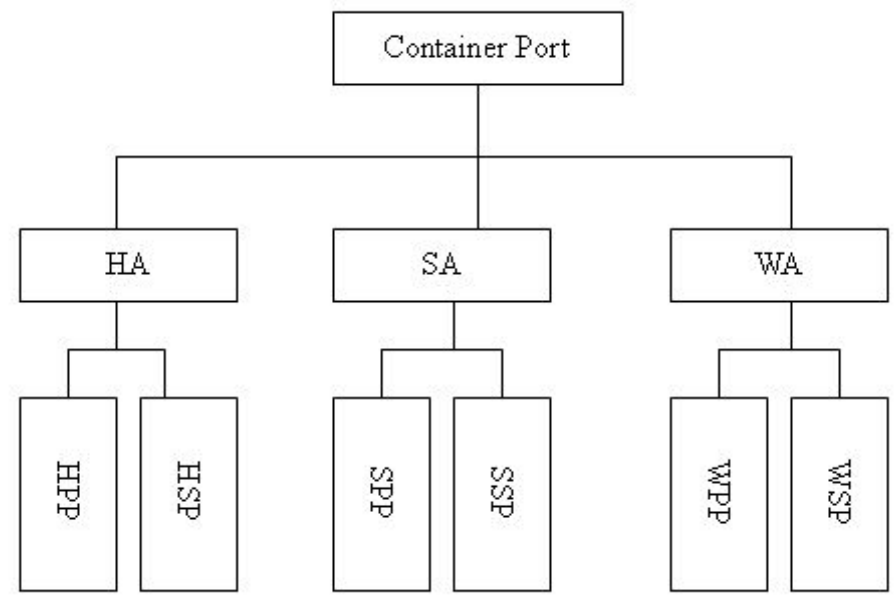

Before investigating the weighting scheme of each process and activity by using ANP, the degree of interrelationship must first be identified. We adapted the Delphi method to characterize the degree of influence on processes/activities, and discussed the activity structure with 15 specialists involved in container port operations. The activity and process influence diagrams are shown below in Figures 4 and 5.

\section{Figure 4.}

Three activities network relation diagram

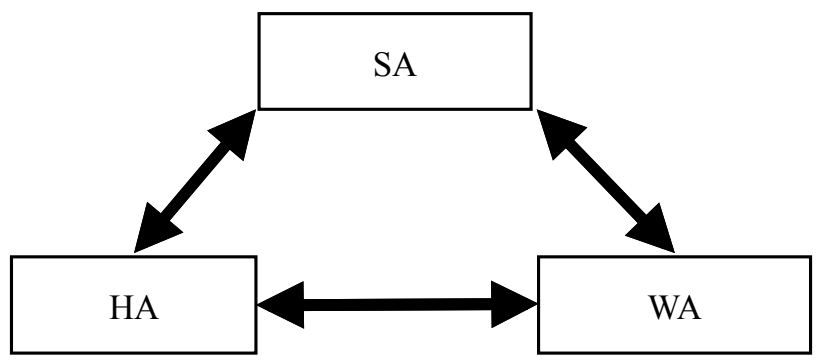

Figure 4 is based on directed graphs, which can separate the involved activities into causal activities in order to better understand causal relationships. Here, the three activities played two roles (i.e., involved activity and causal activity). Digraphs are more useful than directionless graphs because digraphs can demonstrate the directed relationships of activitiesor processes. For example, the arrow from HA to WA 
illustrates the relationship between the two variables, and highlights its influence's significance. Here, these activities are influenced by each other. From the digraph in Figure 4 we can derive a more complex illustration of Figure 5.

Figure 5 .

Six processes netwrork relation diagram

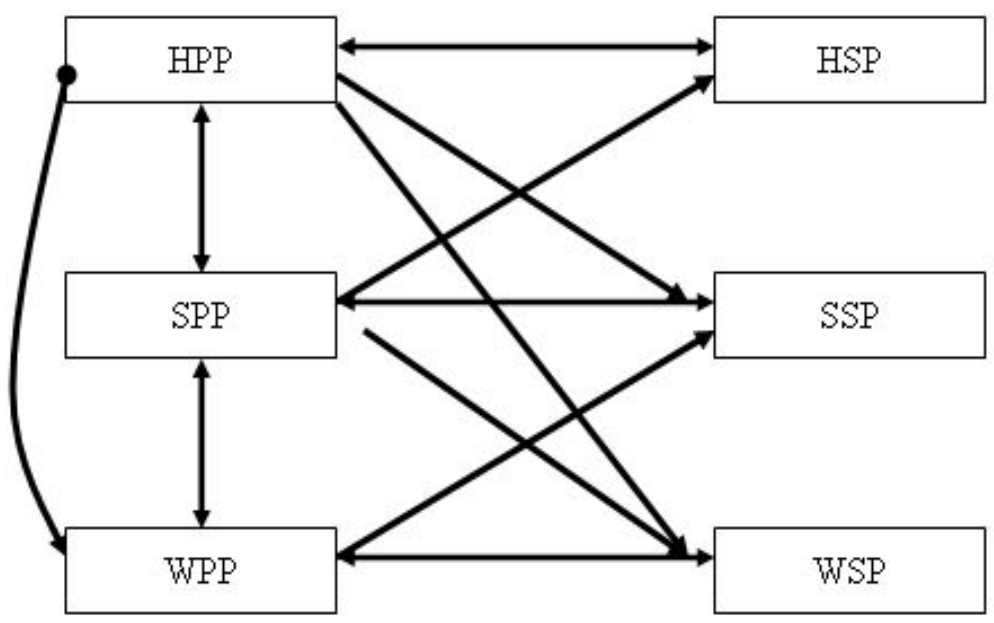

The steps of Section 4.2 can be summarized as follows. The first step investigates the interrelations of the activity and process according to the viewpoints of 15 specialists in container port operations. Through questionnaires, using a binary scale of 0 and 1 ("no influence" and "positive influence"), we asked each respondent to propose the degree of direct influence that each activity/process exerts on another activity/process. 13 questionnaires were returned, with the experts reaching a unanimous consensus on less than $5 \%$ of the questions. From this data, we constructed the process network relation diagram for illustrating the influence between processes. In figure 5, each block represents a process in the container port process. Further, an arrow from the starting process to the destination process shows the effect that the starting process has on the destination process, and the strength of its effect is positive. For example, the HPP affects the SSP and the strength of its effect is positive.

The second phase investigates the importance (weight) that these experts placed on each activity/process. Here, the questionnaire used a scale of $0,1,2$ and 5 to represent a range from "absolutely unimportant" to "absolutely important". The results from these questionnaires are further detailed in Table 8 , and this information will be used within the ANP portion in our model. 
Through conducting the ANP analysis outlined in Section 3, we determined the weights for each process and activity. The fuzzy ANP was applied into the problem of shared inputs' weighting. In the pair-wise comparisonof processes, the decision maker can use a triangular fuzzy number to state the specialists' preferences. We considered the uncertainly associated with the mapping of specialists' perception or judgment to a number. The specialists' perception of common inputs of $\zeta^{h, s}$ and $\zeta^{s, w}$ are vague and ambiguous, hence, cannot be expressed in the definite number. To evaluatethe specialists' preference, pair-wise comparison matrices are structured by using a triangular fuzzy number $(\bar{e}, \tilde{e})$. Here, $\bar{e}$ means the lower bound of the scale and $\tilde{e}$ means the upper bound of the scale. Therefore, we can determine two weights for the shared inputs. The result of $\zeta^{h, s}$ can be calculated by determining its bounds between 0.2 and 0.6. The $\zeta^{s, w}$ is determined via fuzzy ANP between 0.4 and 0.9 . The Table 8 shows the results of the weight of each activity and process.

\section{Table 8.}

Weightings for Each Process and Activity

\begin{tabular}{|c|c|}
\hline $\begin{array}{l}\text { Construct } \\
\text { Measure } \\
\end{array}$ & $\begin{array}{l}\text { Construct Weight } \\
\text { Measure Weight }\end{array}$ \\
\hline HA $\left(r_{h}\right)$ & 0.477 \\
\hline $\operatorname{HPP}\left(r_{h} \zeta^{h}\right)$ & 0.48 \\
\hline $\operatorname{HSP}\left(r_{h} \tilde{\zeta}^{h}\right)$ & 0.141 \\
\hline $\mathbf{S A}\left(r_{s}\right)$ & 0.386 \\
\hline $\operatorname{SPP}\left(r_{s} \zeta^{s}\right)$ & 0.18 \\
\hline $\operatorname{SSP}\left(r_{s} \tilde{\zeta}^{s}\right)$ & 0.052 \\
\hline $\mathbf{W A}\left(r_{w}\right)$ & 0.138 \\
\hline $\operatorname{WPP}\left(r_{w} \zeta^{w}\right)$ & 0.092 \\
\hline$W S P\left(r_{w} \tilde{\zeta}^{w}\right)$ & 0.054 \\
\hline Sum & $\begin{array}{l}1 \\
1\end{array}$ \\
\hline
\end{tabular}




\subsection{Windows Analysis}

Following the assumptions listed in Section 3.4. We will assume six periods for the window width. Window analysis used three container ports for ten years, divided into six-year window lengths of five windows. That is, $u=6, v=10$ and the number of windows is 5 (i.e., $v-u+1$ ). As a result, our observations expand from 30 (three container ports in 10 years) to 90 (5 windows; each window with 18 observations).

\subsection{Multiple-activity Network DEA Analysis}

In the following Model (14), we evaluate the efficiency score of each process of each container port in a unified model. The results are shown in Table 9.

\section{Table 9.}

The Results of MNDEA

\begin{tabular}{|c|c|c|c|c|c|c|c|}
\hline \multirow{2}{*}{ Container Port } & \multirow{2}{*}{$\begin{array}{l}\text { Process } \\
\text { Overall }\end{array}$} & \multicolumn{5}{|c|}{ Efficiency Scores } & \multirow{2}{*}{ Average } \\
\hline & & 2004 & 2005 & 2006 & 2007 & 2008 & \\
\hline \multirow{10}{*}{ Keelung } & HPP & 1 & 1 & 1 & 1 & 1 & 1.00 \\
\hline & HSP & 0.095 & 0.059 & 0.109 & 0.841 & 0.157 & 0.25 \\
\hline & HA & 0.548 & 0.530 & 0.555 & 0.921 & 0.579 & 0.625 \\
\hline & SPP & 1 & 1 & 1 & 1 & 1 & 1.00 \\
\hline & SSP & 1 & 1 & 1 & 1 & 1 & 1.00 \\
\hline & SA & 1 & 1 & 1 & 1 & 1 & 1 \\
\hline & WPP & 1 & 1 & 1 & 1 & 1 & 1.00 \\
\hline & WSP & 0.833 & 0.961 & 0.833 & 0.716 & 0.88 & 0.84 \\
\hline & WA & 0.917 & 0.981 & 0.917 & 0.858 & 0.940 & 0.920 \\
\hline & Overall & 0.863 & 0.865 & 0.865 & 0.962 & 0.875 & 0.89 \\
\hline \multirow{10}{*}{ Taichung } & HPP & 1 & 1 & 1 & 1 & 1 & 1.00 \\
\hline & HSP & 0.873 & 0.035 & 0.067 & 0.5 & 0.073 & 0.31 \\
\hline & HA & 0.937 & 0.518 & 0.534 & 0.750 & 0.537 & 0.655 \\
\hline & SPP & 1 & 1 & 1 & 1 & 1 & 1.00 \\
\hline & SSP & 0.997 & 0.954 & 0.98 & 0.799 & 0.907 & 0.93 \\
\hline & SA & 0.999 & 0.977 & 0.990 & 0.900 & 0.954 & 0.965 \\
\hline & WPP & 1 & 1 & 1 & 1 & 1 & 1.00 \\
\hline & WSP & 1 & 1 & 1 & 1 & 1 & 1.00 \\
\hline & WA & 1 & 1 & 1 & 1 & 1 & 1 \\
\hline & Overall & 0.982 & 0.862 & 0.867 & 0.919 & 0.864 & 0.90 \\
\hline \multirow{10}{*}{ Kaohsiung } & HPP & 1 & 1 & 1 & 1 & 1 & 1.00 \\
\hline & HSP & 0.918 & 0.934 & 0.95 & 0.969 & 0.995 & 0.95 \\
\hline & HA & 0.959 & 0.967 & 0.975 & 0.985 & 0.998 & 0.975 \\
\hline & SPP & 0.836 & 1 & 1 & 0.929 & 1 & 0.95 \\
\hline & SSP & 1 & 0.974 & 1 & 0.952 & 0.998 & 0.98 \\
\hline & SA & 0.918 & 0.987 & 1.000 & 0.941 & 0.999 & 0.965 \\
\hline & WPP & 0.878 & 1 & 1 & 1 & 1 & 0.98 \\
\hline & WSP & 1 & 1 & 1 & 1 & 1 & 1.00 \\
\hline & WA & 0.939 & 1.000 & 1.000 & 1.000 & 1.000 & 0.990 \\
\hline & Overall & 0.948 & 0.989 & 0.993 & 0.98 & 0.999 & 0.98 \\
\hline
\end{tabular}




\subsubsection{Overall performance of three ports}

The results are shown in Table 9, which provides overall efficiency scores for the three ports: Kaohsiung (0.98) $\succ$ Taichung $(0.90) \succ$ Keelung (0.89). Figure 6displays the overall efficiency scores of the three container ports from 2004-2008. As Taiwan's primary gateway for imports and exports, Kaohsiung generally scored higher in efficiency than the other two ports, demonstrating an increase in efficiency within the study's time period. In the case of the other two ports, Taichung ports demonstrated a decrease in efficiency from 2004 to 2005and from 2007-2008, as sedimentation within the port decreased the outputs. Moreover, because the Taipei port is near Keelung, it is predictable that Taipei's container ports will reduce outputs at Keelung from 20072008. However, the two smaller ports illustrated an increase in efficiency from 2006 to 2007, this is attributed to the two ports having lower undesirable outputs in 2007, especially in ships-waiting-time-for-berth. The evidence can be found in the raw data (i.e., average waiting time at the Keelung port was from 3.4 hours to 0.6 hours in 2007, Taichung port had an average of 4.15 hours to 0.6 hours in 2007; But, the average waiting time at Kaohsiung port was from 0.46 to 0.2 hours).

\section{Figure 6.}

The overall efficiency scores of the three container ports

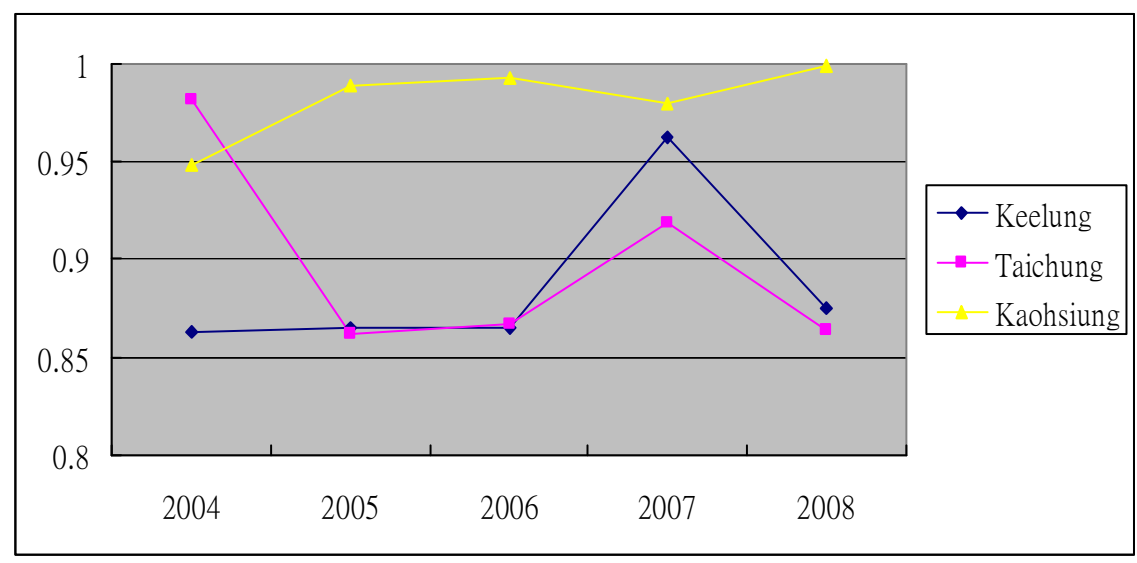

\subsubsection{Activity performance of the three ports}

Compared with the efficiency levels of these activities at the three ports, WA's efficiency seems to be higher than the other two activities, no matter which container ports they are. The three activities' efficiencies at the three ports can be found in Figures 7-9. 


\section{Figure 7.}

The HA Efficiency Scores of the three container ports

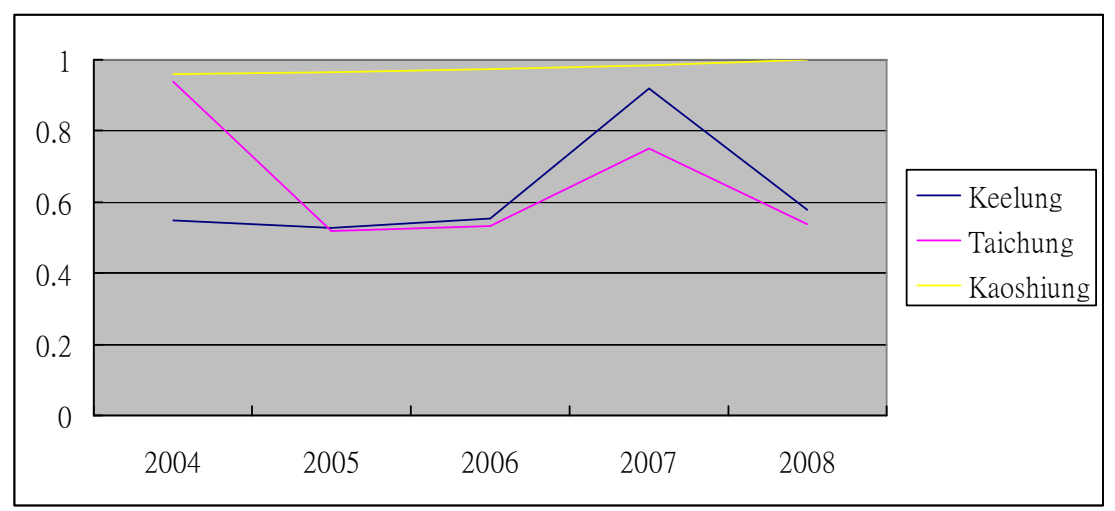

Figure 7 exhibits the HA efficiency scores of the three container ports from 2004-2008. The HA efficiency scores at the Kaohsiung port outperformed the other two ports from 2004 to 2008. In the case of the other two ports, Taichung performed much better in 2004, while the Keelung port performed better in the other periods (i.e., 2005-2008). Moreover, the HA efficiency scores at Taichung and Kaohsiung ports exhibited similar trends (i.e., increasing in period 2005-2007; decreasing in 2007-2008) except for the period in 2004-2005.

It is interesting that the efficiency trends in Figure 7 are similar to those in Figure 6. This demonstrates that HA dominated the overall efficiency scores. Furthermore, Figure 8 demonstrates that SA at the Keelung port performed a higher efficiency score than seen in the two activities.

\section{Figure 8.}

The SA efficiency scores for the three container ports

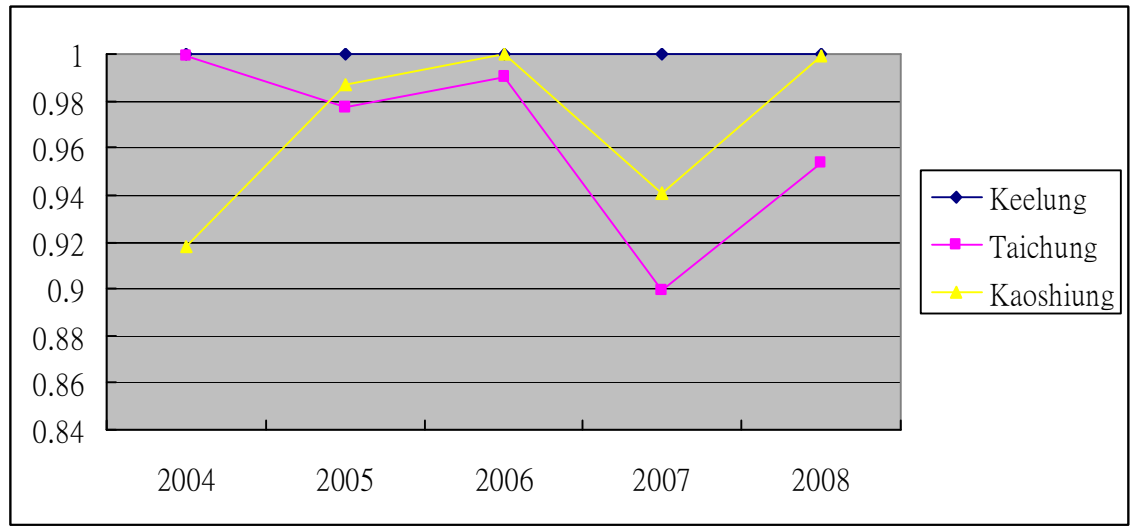


Figure 8 exhibits the SA efficiency scores for the three container ports from 2004-2008. The SA efficiency scores at the Keelung port outperformed the other two ports from 2004 to 2008. In the case of the other two ports, Taichung performed much better in the year 2004, while the Kaohsiung port performed better in the other periods (i.e., 2005-2008). Moreover, the SA efficiency scores at the Taichung and Kaohsiung ports exhibited similar trends (i.e., increasing in periods 2005-2006 and 2007-2008; decreasing in 2006-2007) except for theyear 2004-2005.

\section{Figure 9.}

The WA efficiency scores for the three container ports

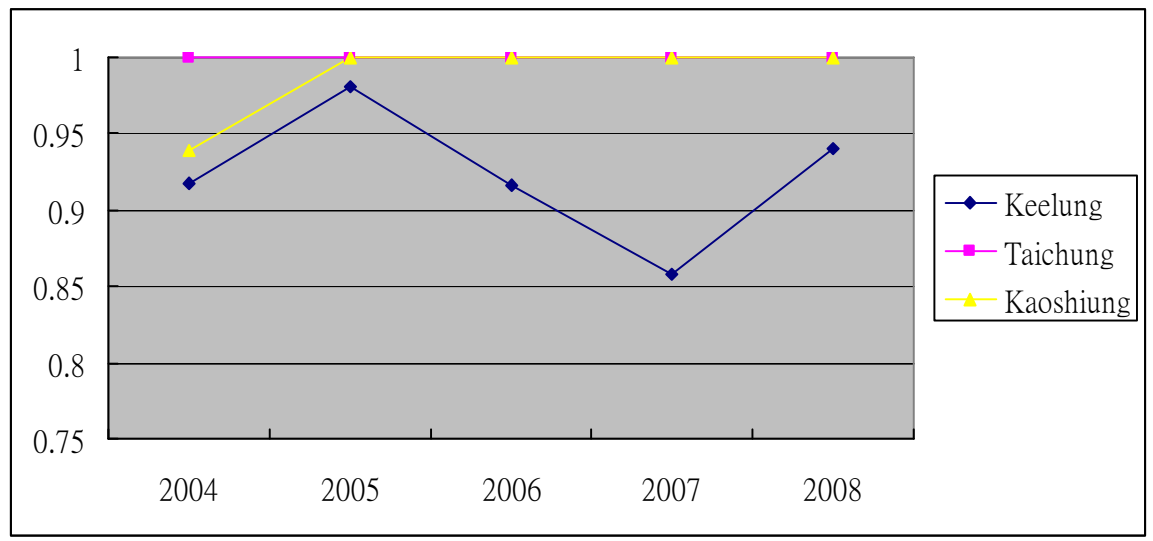

Figure 9 exhibits the WA efficiency scores for the three container ports from 2004-2008. Although the Keelung port showed increasing trends in 2004-2005 and 2007-2008, the port displayed poor efficiency scores when compared with the other two ports. In the case of the other ports, Taichung and Kaohsiung demonstrated the best practice in efficiency from 2004 to 2008, except for Kaohsiung in 2004. Overall, each container port has its strengths and its weaknesses in activity performance. This is the reason why we need to explore the process performance of the three container ports in detail.

Overall, we can conclude that the Kaohsiung port has higher SA efficiency scores when compared to the other two ports. But, in SA, the Keelung port displayed higher efficiency scores than Taichung and Kaohsiung. This demonstrates that the three container ports should maintain their competitive position and continue to improve on their weakest activities. For example, the Keelung port should transfer its resources (i.e., the resources of SA) in order to reduce harbor infrastructures and increase its gross tonnage. 


\subsubsection{Process performance at the three ports}

In summary, the HPP, SPP and WPP at the three ports is more efficient than those of HSP, SSP and WSP, which implies that the three ports are more inefficient in service processes than in production processes. As a result, Taiwan's container ports have a greater advantage in the production process. As for individual activity, the performance of HPP is better than HSP. This suggests that the three container ports should place more emphasis on port services for arriving gross tonnage and reduce the turnaround time in port and the ships waiting time for berth with the exception of the Kaohsiung port.

\section{Discussion of the MNDEA results}

Based on our empirical results, the activities and processes analyzed obtained efficiency scores for the 3 container ports. In Figure 10, the horizontal axis ranks the activity (process) efficiency scores from low to high, while the vertical axis ranks the activity (process) efficiency scores from low to high. Both the horizontal and vertical axes have two critical values: one is higher than the average, while the other is lower than the average. The two axes separate the space into four quadrants.

Figure 10.

Efficiency Sectors

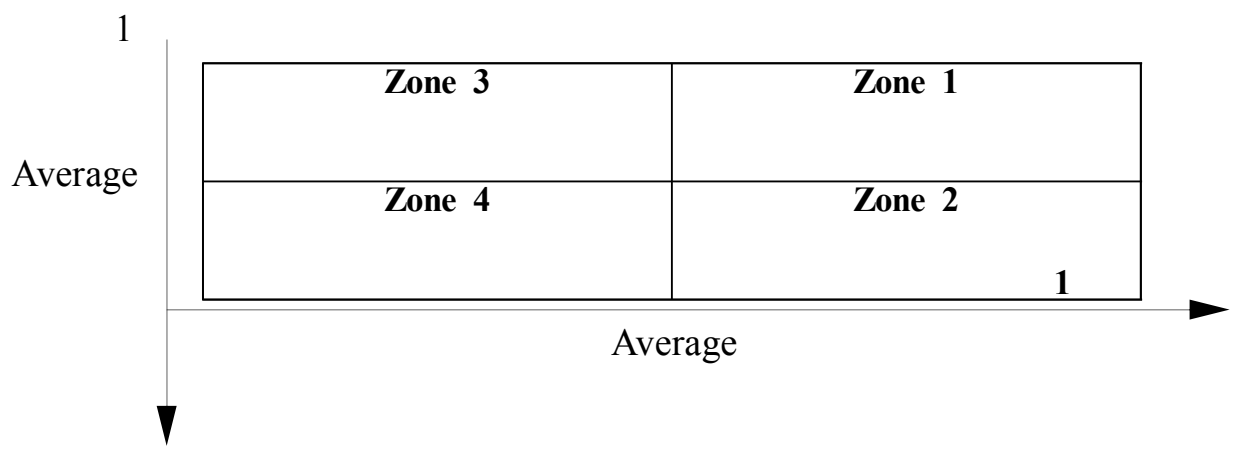

The first quadrant (i.e., Zone 1) represents the high efficiency scores for the horizontal axis and high efficiency scores for the vertical axis. The second quadrant (i.e., Zone 2) represents low efficiency scores for the vertical axis and high efficiency scores for the horizontal axis. The third quadrant represents (i.e., Zone 4) low 
efficiency scores o for the horizontal axis and low efficiency scores o for the vertical axis. The fourth quadrant (i.e.,Zone 3) represents high efficiency scores for the vertical axis and low efficiency scores for thehorizontal axis. Based on Figure 10, we are able to construct the 3 container ports into the decision matrix, as shown in Table 10.

Table 10.

Efficiency of the Three Container Ports

\begin{tabular}{ccccccc}
\hline Type & $\begin{array}{c}\text { Horizontal } \\
\text { Axis }\end{array}$ & $\begin{array}{c}\text { Vertical } \\
\text { Axis }\end{array}$ & Zone 1 & Zone 2 & Zone 3 & Zone 4 \\
\hline & HA & SA & & Kaoshiung & Keelung & Taichung \\
A & HA & WA & Kaoshiung & & Taichung & Keelung \\
& SA & WA & & Keelung & $\begin{array}{c}\text { Taichung } \\
\text { Kaoshiung }\end{array}$ & \\
\hline & HPP & SPP & $\begin{array}{c}\text { Keelung } \\
\text { Taichung }\end{array}$ & & Kaohsiung & \\
\hline B & HPP & WPP & $\begin{array}{c}\text { Taichung } \\
\text { Kaoshiung }\end{array}$ & & Keelung & \\
& SPP & WPP & Taichung & Keelung & Kaoshiung & \\
\hline & HSP & SSP & Kaoshiung & & Keelung & Taichung \\
\hline C & HSP & WSP & Kaoshiung & & Taichung & Keelung \\
& SSP & WSP & Kaoshiung & Keelung & Taichung & \\
\hline & HPP & HSP & Kaoshiung & & Keelung & \\
& WPP & WSP & Taichung & Keelung & Kaoshiung & \\
\hline D & SPP & SSP & Keelung & Taichung & Kaoshiung & \\
\hline
\end{tabular}

Table 10 shows the efficiency of the three container ports based on activity (process) vs. Process (activity). This table shows how to adjust the resources to the right process in order to improve the efficiency. For example, in the case of HA vs. SA, the container ports in Zone 3 should improve their harbor management activity efficiency in order to improve their overall efficiency, because these container ports have reached the SA's average of 3 container ports. On the contrary, we find that the Taichung port should improve its efficiency in both harbor management and stevedoring activities. Likewise, the Kaoshuing port should improve its stevedoring activities (in the Zone 2). Based upon this information, we can actually determine how to adjust the resources for each container port. When comparing the SA vs. WA, data from the Keelung port it is indicated that the stevedoring activity's efficiency should be improved, and that the Taichung and Kaoshiung ports should attempt to impove 
both SA and WA. The case of type B demonstrates that these three container ports seem to have higher efficiency scores regarding production processes, regardless of the production process type. Taiwan's container ports were able to control staff and machine reductions in each time period. However, the case of type $\mathrm{C}$ demonstrated that the Taichung and Keelung container ports need to improve their services including reducing ship wait times and loading times, and increasing desirable outputs (e.g., $y_{f 1}^{h}, y_{f 1}^{s}, y_{f 2}^{s}$ and $y_{f 1}^{w}$. Lastly, the case of type D illustrated that Kaoshiung has better harbor production and service abilities (i.e., high HSP and HPP), Taichung can provide decent wearhouse production and service abilities (i.e., high WSP and WPP), and Keelung has strong advantages on production and service abilities regarding stevedoring (i.e., high SSP and SPP)..

\section{Conclusions}

As container ports are an important link in the logistics chain, the level of port efficiency has a huge impact on a country's productivity and competitiveness. Moreover, container port operations have become increasingly complex as new technologies impose new requirements in infrastructure and materials handling. Container port operational performance is an important criterion for the international competitiveness of a country. When evaluating the functionality of container port operations, analysts should not only examine harbor management activity, but also stevedoring and warehousing concurrently. This paper develops a multi-activity network DEA approach which allows for the incorporation of harbor management, stevedoring and warehousing technologies simultaneously in a model in order to evaluate the technical efficiency of the three major container ports in Taiwan.

The proposed model along with the ANP and the window analysis explicitly not only consider the interactions between various activities and processes that make up container port operation, but also provide solutions to the weighting schemes and dimensionality problems. By using this model, the problems of common inputs and intermediate products characterizing container port operations are taken into account in an integrated framework simultaneously with the consideration of undesirable outputs.

Empirical results provide the following findings. When comparing the efficiency of the three activities at the three ports, the WA's efficiency seems to be higher than the other two activities, no matter which container ports they are. The three ports are more inefficient in service process than they are in production activities, suggesting that the three container ports should place more emphasis on port services for incoming 
gross tonnage and reduce the turnaround time in port and for the ships waiting time for berth. Moreover, based upon the information found in the decision matrix, the results show how to adjust the present resources in order to improve the process and improve overall efficiency.

Despite our results, this study also has certain limitations. First, we measured the degree of influence of container ports only through the Delphi approach rather than through a more systematic model (e.g., Decision Making Trial and Evaluation Laboratory (DEMATEL)). Secondly, our study excludes environmental factors, which might affect the results. Lastly, we treated window analysis only as a way to take account of maxims discrimination power, but didn't consider that the technology doesn't change in the window. These above-mentioned limitations may be resolved in future works. 


\section{REFERENCE}

Barros, C.P. (2003a), Incentive Regulation and Efficiency of Portuguese Port Authorities, Maritime Economics \& Logistics 5(1), 55-69.

Barros, C.P. (2003b), The Measurement of Efficiency of Portuguese Seaport 26 Authorities with DEA, International Journal of Transport Economics 30(3), 335-354.

Barros, C.P., and Athanassiou, M. (2004), Efficiency in European Seaports with DEA: Evidence from Greece and Portugal, Maritime Economics \& Logistics 6, 122-140.

Barros, C.P. (2006), A Benchmark Analysis of Italian Seaport Using Data Envelopment Analysis, Maritime Economics and Logistics, 8, 347-365.

Beatriz Tovar de la Fe, Sergio Jara-Díaz, and Lourdes Trujillo Castellano, (2004), Funciones de producción y costes y su aplicación al sector portuario. Una revisión de la literatura, Documentos de trabajo conjunto ULL-ULPGC 2004-06, Facultad de Ciencias Económicas de la ULPGC.

Bendall, H., and Stent, A. (1987), On Measuring Cargo Handling Productivity, Maritime Policy \& Management, 14(4), 337-343.

Charnes, A., Clark, T., Cooper W. W., and Golany, B. (1985), A developmental study of data envelopment analysis in measuring the efficiency of maintenance units in U. S. Air Forces. In R. Thompson \& R. M. Thrall (Eds.), Annals of Operational Research, 2, 95-112.

Chung, Y. H., Färe, R. and Grosskopf, S. (1997), Productivity and Undesirable Outputs: A Directional Distance Function Approach, Journal of Environmental Management 51, 229-240.

Chung, C.C., and Hwang, C.C. (2005), Analysis on Vessel Registration and Operational Performance of Bulk-shipping, In Proceedings of the eastern Asia society for transportation studies 5, 631-646.

Coto Millan, P., Banos Pino, J. and Rodrigues A. (2000), Economic Efficiency in Spanish Ports: Some Empirical Evidence, Maritime Policy \& Management 27(2), 169 175.

Cullinane, K., and Song, D.W. (2003),A Stochastic Frontier Model of the Productive Efficiency of Korean Container Terminals, Applied Economics, 35, 251-267.

Cullinane, K, Song, D.W, and Gray, R. (2002), A Stochastic Frontier Model of the Efficiency of Major Container Terminals in Asia: Assessing the Influence of Administrative and Ownership Structures, Transportation Research Part A 36, 743-762.

Cullinane, K., Song, D.W., Ji, P., and Wang, T.F. (2004), An Application of DEA Windows Analysis to Container Port Production Efficiency, Review of Network Economics, 3, 2, 184-206. 
Cullinane, K. P. B. Song, D.W., and Gray, R. (2002), A Stochastic Frontier Model of the Efficiency of Major Container Terminals in Asia: assessing the influence of administrative and ownership structures, Transportation Research Part A, (36), 734-762.

Cullinane, K. Song, D.W. and Wang, T. F. (2005), The Application of Mathematical Programming Approaches to Estimating Container Port Production Efficiency. Journal of Productivity Analysis 24, 73-92.

Estache, A., Tovar de la Fé, B. and Trujillo, L. (2004), Sources of efficiency gains in port reform: A DEA decomposition of a Malmquist index for México, Utility Policy, 30 (4), 221-230.

Estache, A., Gonzalez, M., and Trujillo, L. (2002), Efficiency Gains from Port Reform and the Potential for Yardstick Competition: Lessons from Mexico, World Development 30(4), 545-560.

Estache, A.; Gonzalez, M., and Trujillo, L. (2001), Efficiency Gains from Port Reforms and the Potential for yardstick Competition: Lessons from Mexico, World Development 30(4): pp. 545-560.

Itoh, H. (2002), Efficiency changes at major container ports in Japan: Awindow application of DEA, Rurds 14, 133-152.

Liu, Z. (1995), The Comparative Performance of Public and Private Enterprises: The Case of British Ports, Journal of Transport Economics and Policy 29(3), 263-274.

Lovell, C.A.K, Pastor, J.T, and Turner, J.A. (1995), Measuring macroeconomic performance in the OECD: A comparison of European and non-European countries, European Journal of Operation Research 87, 507-518.

Leibenstein, H., and Maital, S. (1992),Empirical Estimation and Partitioning of X-inefficiency: A Data Envelopment Approach. American Economic Review 82, 428-433.

Mar Molinero, C. (1996), On the joint determination of efficiencies in a data envelopment analysis context, The Journal of the Operational Research Society, 47(10), 1279-1279.

Notteboom, T., Coeck, C., and Van de Broeck, J., (2000), Measuring and explaining the relative efficiency of container terminals by means of Bayesian stochastic frontier models, Journal of Maritime Economics and Logistics 2(2), 83-106.

Park, R.K. and De, P. (2004), An Alternative Approach to Efficiency Measurement of Seaports, Maritime Economics and Logistics, 6(1), 53-69.

Pastor, J.T., Ruiz, J.L., and Sirvent, I. (1999),An enhanced Russell graph efficiency measure, European Journal of Operational Research 115, 596-607.

Roll Y., and Hayuth, Y. (1993), Port Performance Comparison Applying Data Envelopment Analysis (DEA), Maritime Policy and Management 20(2), 153-161. 
Tzeng, G. H., Lin, C. W. and Opricovic, S. (2005), Multi-criteria Analysis of Alternative-fuel Buses for Public Transportation. Energy Policy 33:1373 1383.

Tzeng, G. H., Huang, J. J. and Ong, C. S. (2006), optimal fuzzy multi-criteria expansion of competence sets using multi-objectives evolutionary algorithm. Expert Systems with Applications 30,739-745.

Tongzon, J. (1995), Determinants of port performance and efficiency, Transportation Research, 29A (3), 245-252.

Tongzon, J., and Heng, W. (2005), Port privatization, efficiency and competitiveness: Some empirical evidence from container ports (terminals), Transportation Research Part A - Policy and Practice 39, 405-424.

Tongzon Jose (2001).,Efficiency Measurement of selected Australian and other international ports using data DEA,Transportation Research Part A, Policy and Practice 35(2), 113-128.

Thanassoulis, E., and Dyson, R.G. (1992), Estimating Preferred Target Input-Output Levels using Data Envelopment Analysis, European Journal of Operational Research 56, 80-97.

Valentine V.F., and Gray R. (2001), The measurement of port efficiency using data envelopment analysis, Proceeding of the Ninth World Conference on Transport Research, Seoul, 22-27 July.

Valentine, V.F., and Gray, R. (2002), An Organizational Approach to Port Efficiency, IAME 2002, Panama.

Wang T., Cullinane K, and Song D.W. (2003),Container Port Production Efficiency: A Comparative Study of DEA and FDH Approach, Journal of the Eastern Asia Society for Transportation Studies 5, 698-713.

Yu, M.M., and Lin, T.J. (2008), Efficiency and Effectiveness in Railway Performance Using a Multi-activity Network DEA Model, OMEGA. The International Journal of Management Science 36(6), 1005-1017. 